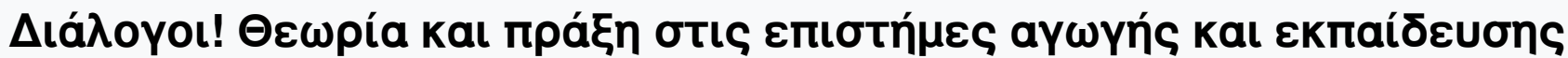

Tó 6 (2020)

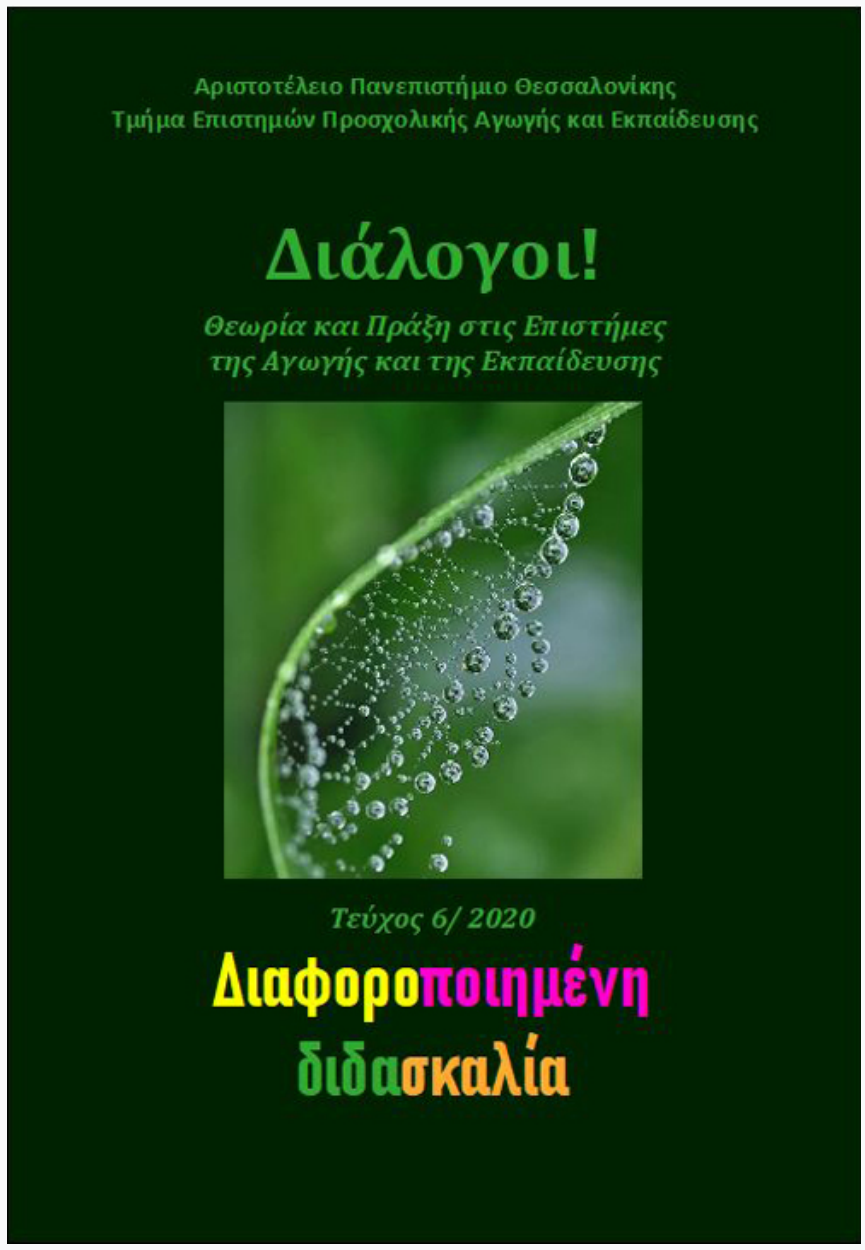

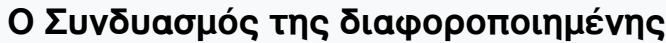

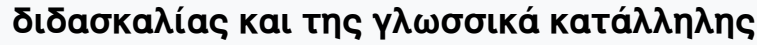

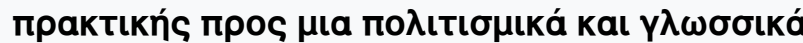

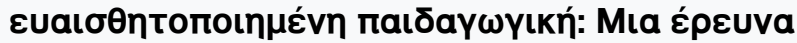

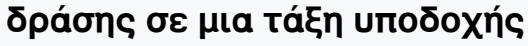

Sophia Dimadi, Magdalini Vitsou

doi: $10.12681 /$ dial.22983

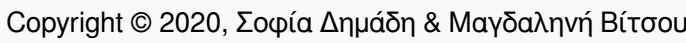

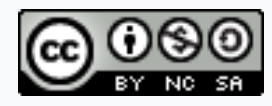

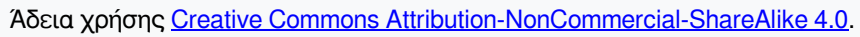

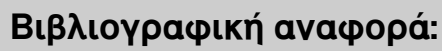

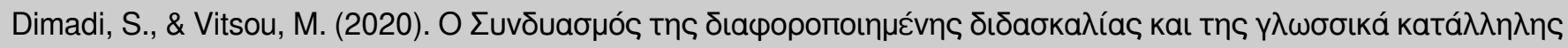

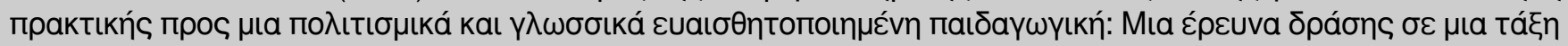

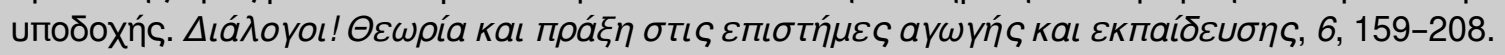

https://doi.org/10.12681/dial.22983 


\title{
Exploring the impact of blending Differentiated Instruction with Linguistically Appropriate Practice towards a Culturally and Linguistically Responsive Pedagogy: An action research in a Reception Class
}

\author{
Sophia Dimadi \\ Hellenic Open University
}

\author{
Magdalini Vitsou \\ University of Thessaly
}

\begin{abstract}
The present action research examines the impact of Differentiated Instruction and Linguistically Appropriate Practice on migrant students' education. Drawing on data from the academic work of many scholars (Tomlinson, Santamaria, Valiandes, Sfyroera, Chumak-Horbatsch), the effect of mixing the two practices in the learning process and students' perceptions on using the new practice are examined.

In the context of this research, seven students of migrant background (10-12 years) participated in an intervention of five research cycles. The research was conducted in a Reception Class of an Elementary School of Piraeus, in Spring 2019. The researcher-educator through participatory observation and research diaries collected the data and reflected on the results of each research cycle. Qualitative data from the focus group discussion of students about their perceptions of new practice were also collected.

Findings showed that the blending of the two approaches had positive effects on learners in terms of engagement as they showed increased motivation, their interpersonal relationships improved impressively, while they all accepted the new practice with no serious disinclinations. From the students' perspective, they all positively commented on the use of multiple materials, the playful nature of the activities as well as the cultural and linguistic awareness promoted by the intervention.
\end{abstract}

Keywords: Differentiated Instruction, Linguistically Appropriate Practice, action research, culturally and linguistically diverse students

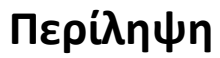

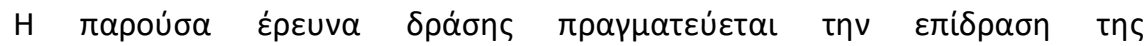

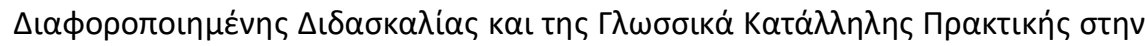

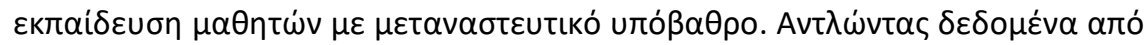

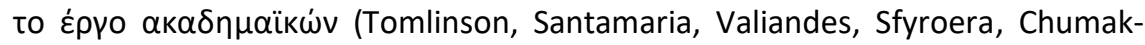

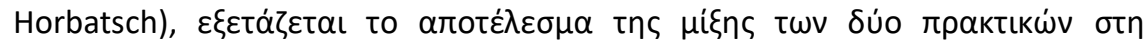

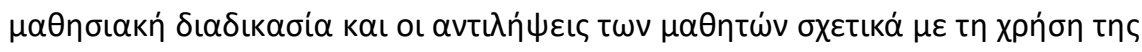

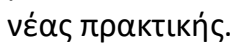

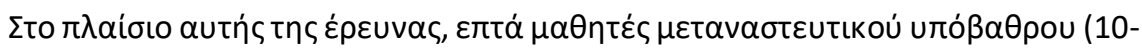

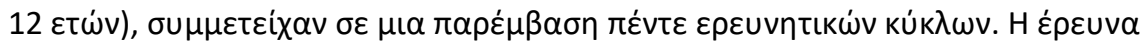

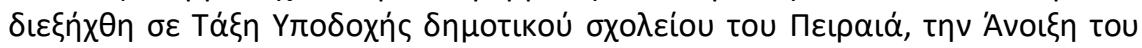

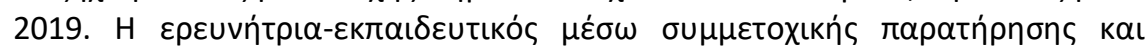

Correspondent author: Magdalini Vitsou, mvitsou@uth.gr, Laboratory Teaching Staff, Department of Early Childhood Education, University of Thessaly 


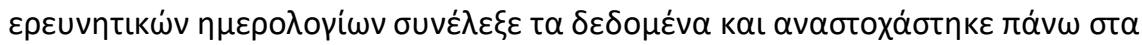

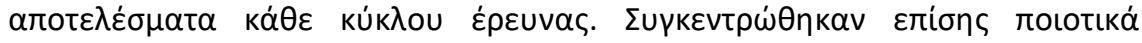

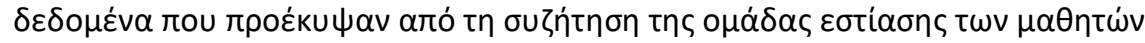

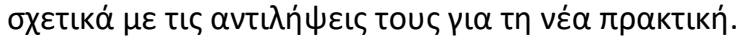

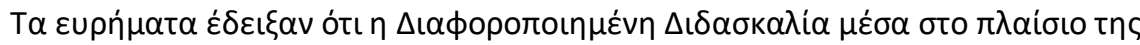

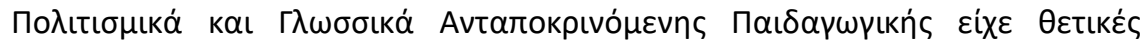

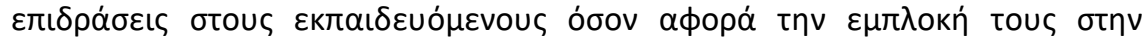

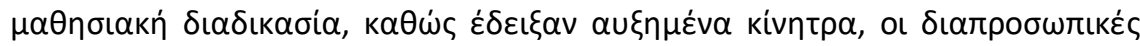

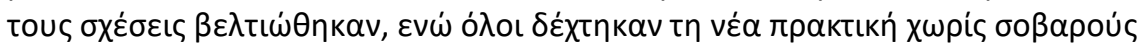

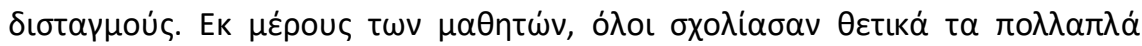

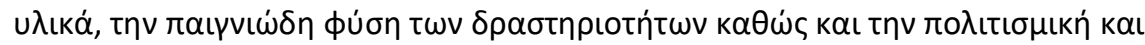

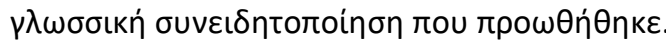

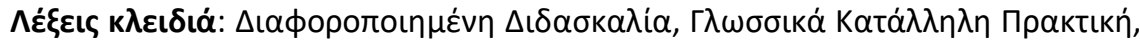

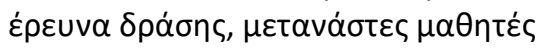

\section{Introduction}

Heterogeneity of language classrooms is a predominant factor affecting the learning process. Achievement gaps are noticed, as students differ in various ways. Many of them are identified with learning disabilities, others are gifted, others differ linguistically and culturally, others come from diverse socioeconomic backgrounds while others have different interests and learning styles. In the Greek educational context, classrooms' heterogeneity was mainly attributed to the mobilization of populations, due to the migratory trajectories and the recent refugee crisis (Gkaintartzi, Kiliari, \& Tsokalidou, 2016; Sfyroera, 2004). Especially since 2015, the continuing refugee flows have contributed to the increase of students of refugee or migrant background in the Greek educational system. Only in 2017, 20.300 refugee and other migrant children were hosted in the country (Ziomas, Capella, \& Konstantinidou, 2017).

Drawing on Krumm's and Pultzar's (2008) statement that migrant learners differ considerably from other foreign language learners due to their diverse social, cultural and linguistic backgrounds, it seems aimless to design a language course bound for a homogeneous group. Thus, tailor-made courses should be designed, corresponding to migrants' needs towards a culturally and linguistically responsive pedagogy (Hollie, 2012). This entails the need to adjust the curriculum and the materials used, so that all students have access to meaningful instruction of high quality. Consequently, differentiating instruction to respond to learners' needs, maximizes students' learning outcomes (Tomlinson, 1999; Tomlinson \& Eidson, 2003). However, there is limited research providing educators with practical guidelines about the way differentiation could be applied to respond to culturally and linguistically diverse, henceforth referred to as CLD students (Santamaria, 2009). Thus, although differentiated instruction, henceforth referred to as $\mathrm{DI}$, has been examined within many groups of students (gifted, with learning difficulties), CLD students were not sufficiently investigated within the framework of DI. Moreover, since the focus is CLD students, meaningful differentiated instruction should be set in the framework of culturally and linguistically responsive pedagogy, henceforth referred to as CLR pedagogy. A way to implement this is to supplement DI strategies with Linguistically Appropriate Practice (henceforth referred to as LAP) that Chumak- 
Horbatsch (2012) argues about. LAP framework is an inclusive practice, taking advantage of the linguistic and cultural diversity of the class.

\section{Theoretical Background}

\section{Conceptualizing Differentiated Instruction}

Teachers, not being able to ignore the heterogeneity of language classrooms, may respond to the call of the democratization of education and the 'equity of condition' (Lynch \& Baker, 2005), by applying DI. DI is not just another teaching practice, it is a philosophy, an ethos, an alternative perspective to teaching and learning (Santamaría, 2009; Valiandes, Neophytou, \& Hajisoteriou, 2018). Tomlinson (1999, 2001), an expert in the field of $\mathrm{DI}$, argues that teachers who cater to their students' diverse needs, adopt this new teaching philosophy, where teaching and learning routines are modified in order to address learners' varying levels of readiness, interests and learning profiles. Thus, DI addresses all students: those who find school easy and those who find it difficult (Lawrence-Brown, 2004). Consequently, DI is a step toward social justice and equity in education, as it is a student-centered approach, where the teacher is a facilitator of learning (Koutselini, 2006; Koutselini \& Agathangelou, 2009).

Many scientific fields are related to DI such as gifted education (Van Tassel-Baska, 1992), multiple intelligence theories (Gardner, 1983), brain research (Greenleaf, 2003) and bilingual and multilingual education (Banks et al., 2001). More precisely, although DI initially targeted specific groups, such as gifted students, over the years it addressed students with disabilities and more recently students with difficulties deriving from their cultural and linguistic diverse backgrounds (Santamaría, 2009). Especially for the latter group of students, their varying needs are more apparent to educators, rather than those of gifted students or students with learning difficulties (Sfyroera, 2004). This is due to the overt differences deriving from their different linguistic backgrounds.

According to Tomlinson and Imbeau (2010) the curriculum-related elements that can be modified in a differentiated lesson are the following: Content, Process, Product, and Affect. Differentiation of content refers to what students learn. Differentiation of process refers to how students learn, namely in which ways students appropriate the new knowledge. Differentiation of product refers to how students demonstrate what they've learned. Moreover, the impact of students' affect, namely, their feelings and emotions on their learning, triggers certain behaviors. Students' emotional state has an impact on their motivation consequently, it is interrelated with curriculum objectives. Apart from the emotional classroom climate, the physical learning environment can also be modified in DI (Tomlinson, 2001).

Students differ in terms of their level of readiness, their interests and their learning profiles (Tomlinson et al., 2003). Valiandes and Koutselini (2008) added students' socioeconomic status and their self-image as both of them are related to students' academic growth (Chapman, Lambourne \& Silva, 1990). Differentiation of the previously mentioned elements should be based on these differences. The term student's readiness refers to his/her current knowledge on a specified concept. Furthermore, stimulating students' interest is a key element in DI. From a psychological aspect, students when engaging in interesting tasks may be in the state of flow, a term coined to describe the 
psychological state of complete involvement, where time and fatigue disappear (Csikszentmihalyi, 2014). Flow is triggered by interest and when experienced, it serves as a catalyst for appropriating new knowledge. Lastly, DI takes into account variance in terms of learning profile which is "a preference for taking in, exploring, or expressing content" (Tomlinson \& Imbeau, 2010, p. 17). This preference mainly depends on factors such as the learning style, the thinking style, the gender and even the culture.

\section{Conceptualizing Linguistically Appropriate Practice}

An inclusive practice, LAP, is proposed by Chumak-Horbatsch (2012). LAP invests in the dual linguistic environments and needs of CLD students while providing language awareness for all. In order to promote LAP, Chumak-Horbatsch suggested a series of LAP activities conducted in a classroom which is physically set as a multilingual environment. These activities are suggestions that educators may adapt and extend in order to correspond to students' needs, as initially they were designed for pre-school-aged students.

As described by Chumak-Horbatsch (2012), LAP is a new approach to teaching CLD students. Their prior linguistic and cultural backgrounds are not seen as a deficit. On the contrary, CLD students are viewed as emergent bilinguals (García, 2009c), recognizing the importance of home languages in the acquisition of the classroom language (Baker, 2006; Cummins, 2001a, 2001b; Wong Fillmore, 2000). LAP draws on the notion of dynamic bilingualism coined by García (2009a, 2009b). García argues that bilinguals have one linguistic system which incorporates features of both languages in a dynamic way. Hence, in order to deal with communicative circumstances, they use their full linguistic repertoire, by translanguaging (Baker, 2006; García, 2009b).

\section{Blending Differentiated Instruction with Linguistically Appropriate Practice}

Both approaches, DI and LAP share common key elements and a common philosophy. They both invest in students' diverse needs and they aim at including equally all learners in the learning process. Also, both teaching practices address students who are marginalized, not being able to meet their peers academically in the classroom. Despite the similarities, the two approaches are investigated separately from each other. The main difference between the two approaches is that DI focuses more on academic diversity, whereas LAP focuses more on linguistic and cultural diversity. Although there is a focus on linguistic diversity in the context of $\mathrm{DI}$, still its central focus is to respond to academic diversity (Tomlinson, Brimijoin, \& Narvaez, 2008). Subsequently, DI that just acknowledges diversity, without altering the teaching practices, risks being characterized as a colorblind pedagogy (Santamaría, 2009).

Furthermore, research showed that $\mathrm{DI}$ is portrayed as a facilitating teaching approach for learners of migrant background by promoting language learning and raising academic attainment (Hajisoteriou, 2012). However, there is a void in the literature, as experts in DI fail to provide practitioners with practical guidelines showing how DI can benefit CLD students (Tomlinson, 2003). Additionally, scholars have pinpointed DI's limited focus on students' prior experiences, talents and cultural and linguistic diversity (Tomlinson et al., 2008). Thus, Tomlinson realizes that CLD students' needs should be addressed in the context of DI. She states: "you can only care for the child when you 
understand what it is like to be part of the child's culture, what it is like to be unable to speak the language of the classroom" (Tomlinson, 2003, p. 67).

LAP, as mentioned, embraces and deploys cultural and linguistic plurality. Thus, applying LAP activities within the framework of DI may be the optimum way to maximize learning outcomes. Santamaría (2009, p. 240) argues that DI can benefit CLD learners when "it is purposefully adjusted to respond to cultural and linguistic diversity in content, process, and product". Towards this orientation, scholars claim that DI per se is not sufficient if it is not set in the broad context of Culturally Responsive Teaching, henceforth referred to as CRT (Valiandes et al., 2018).

Ladson-Billings (2001) has provided specific indicators of CRT. Firstly, through CRT academic achievement is fostered. Educators encourage academic achievement by investing in students' capabilities and defining standards for everyone. Secondly, cultural competence should be cultivated. Thirdly, sociopolitical consciousness should be promoted. More precisely, teachers who espouse CRT should know the larger sociopolitical context within which educators and students live. Moreover, educators' aim should be the public good. So, planning the best academic experiences for students, impacts not only on their academic growth but on professionals' lives also. Extending the term of CRT, the author adds that DI could be set in the context of CLR pedagogy which entails characteristics of CRT (Gay, 2010; Ladson-Billings, 2001; Richards, Brown, \& Forde, 2007) and of Linguistically Responsive Teaching - LRT (Lucas \& Villegas, 2011). Through CLR pedagogy, cultural and linguistic diversity are viewed as resources, rather than deficits. LAP activities are grounded on the principles of CLR pedagogy.

Research shows that CLD students face difficulties in school due to limited or no command of the classroom language (Janta \& Harte, 2016). Their low academic achievement often results in feelings of isolation and exclusion (Heckmann, 2008). Moreover, diversity in classrooms is seen reluctantly by teachers, if not negatively, and students' bilingual identities are often invisible (Tsokalidou, 2005, 2012). Furthermore, educators seem to be unfamiliar with bilingual and multilingual education and the aims these fields propose (Tsokalidou, 2005). Concerning the implementation of DI strategies in the learning process, research showed that educators are not familiar with adapting the materials, planning tailor-made lessons and changing evaluation procedures (Johnsen, Haensly, Ryse, \& Ford, 2002). Therefore, in this research, the author proposes the practical implementation of DI blended with LAP, in order to provide insight into the learning outcomes, as well as into students' perceptions of both approaches.

\section{Purpose of the study and research questions}

The researcher of this study was also the educator of CLD students with diverse linguistic and academic needs. During the educational process, the main problem observed by the researcher was that students did not demonstrate the desired learning outcomes, as they were often disinterested and frustrated by the whole-class instruction, due to their varied needs. Moreover, students' bad relationships, which were observed during the lessons, by the researcher prior the intervention, impeded the learning process. Hence, this problematic condition triggered the pursuit of improved teaching practices in order to enhance academic achievement. 
More precisely, the purpose of this study was to investigate the impact of a theory-to-practice approach used to reach and teach CLD students when the teacher is a monolingual educator. The study intended to investigate the way DI was applied in the context of CLR pedagogy. Thus, DI was blended with LAP in order to explore how this combination impacts on a group of CLD students attending a Reception Class in a public primary school of Piraeus, Greece.

Hence, the main objective of this research was to answer the following question:

Does Differentiated Instruction when blended with LAP activities benefit CLD learners during the learning process?

In order to answer this question two sub-questions should be answered:

1. What is the impact of Differentiated Instruction blended with Linguistically Appropriate Practice activities on students' engagement in the learning process?

2. How do students perceive the use of Differentiated Instruction blended with Linguistically Appropriate Practice activities during the learning process?

\section{Method}

\section{Research Design}

The research holds to the philosophical assumptions of the transformative worldview. CLD students are educationally marginalized, as their full linguistic repertoire is neglected. Hence, students' empowerment during the learning process by bringing to the foreground their competencies and languages is necessary, in the name of democratization of education.

Action research is conducted through a qualitative design (Somekh, 2006). In this qualitative action research design, conducted in the natural setting of a primary school, students' reactions towards the implementation of DI blended with LAP was investigated via participatory observation and focus group. Emerging themes were analyzed in order to generate knowledge. In Table 1 a timetable of the research cycles and the focus group discussion is presented.

\begin{tabular}{|l|l|}
\hline Date & Research steps \\
\hline $02 / 04 / 2019-05 / 04 / 2019$ & 1st research cycle/data collection/data analysis/reflection \\
\hline $08 / 04 / 2019-12 / 04 / 2019$ & 2nd research cycle/data collection/data analysis/reflection \\
\hline $15 / 04 / 2019-19 / 04 / 2019$ & 3rd research cycle/data collection/data analysis/ reflection \\
\hline $06 / 05 / 2019-10 / 05 / 2019$ & 4th research cycle/data collection/data analysis/reflection \\
\hline $13 / 05 / 2019-17 / 05 / 2019$ & 5th research cycle/data collection/data analysis/reflection \\
\hline $21 / 05 / 2019$ & Focus group discussion \\
\hline
\end{tabular}

Table 1

Research steps

Three thematic units were chosen during the five research cycles: Nutrition, Neighborhood and Clothing. These thematic units were chosen as they were suitable for applying on them a LAP orientation. Moreover, the researcher asked students if they were 
interested in engaging with these thematic units and they all responded positively. During the research cycles, a 21-hour teaching intervention was implemented. In Table 2 the activities per unit are presented.

\begin{tabular}{|l|l|l|l|}
\hline Research cycle & Activities & Intervention hours & Thematic Unit \\
\hline 1st & 1,2 , anchor activity & 4 & Nutrition \\
\hline 2nd & 3,4 & 4 & Nutrition \\
\hline 3rd & 5,6 & 5 & Neighborhood \\
\hline 4th & 7,8 & 4 & Neighborhood \\
\hline 5th & $\begin{array}{l}\text { Learning center } \\
\text { activities }\end{array}$ & 4 & Clothing \\
\hline
\end{tabular}

Table 2

Teaching interventions per thematic unit

In Table 3, the learning objectives of each research cycle respectively, as well as the differentiation strategies that were used are presented.

\begin{tabular}{|c|c|c|c|}
\hline $\begin{array}{l}\text { Research } \\
\text { cycle }\end{array}$ & Activity & Learning objectives & DI strategy \\
\hline \multirow{3}{*}{$1^{\text {st }}$} & 1 & $\begin{array}{l}\text { To identify the ingredients of a recipe. } \\
\text { To match each ingredient to its category. }\end{array}$ & $\begin{array}{l}\text { Differentiation of } \\
\text { product } \\
\text { depending on } \\
\text { student's } \\
\text { readiness }\end{array}$ \\
\hline & 2 & $\begin{array}{l}\text { To describe a recipe. } \\
\text { To understand the difference between the } \\
\text { menu dishes. }\end{array}$ & Tiered activity \\
\hline & $\begin{array}{l}\text { Anchor } \\
\text { activity }\end{array}$ & To engage in assignments related to Nutrition. & Think-tac-toe \\
\hline \multirow[b]{2}{*}{$2^{\text {nd }}$} & 3 & To write a text describing a recipe. & RAFT strategy \\
\hline & 4 & $\begin{array}{l}\text { To read a menu. } \\
\text { To revise the kinds of dishes. } \\
\text { To order dishes in a restaurant. }\end{array}$ & $\begin{array}{l}\text { Differentiation of } \\
\text { content depending } \\
\text { on interests }\end{array}$ \\
\hline \multirow[t]{2}{*}{$3^{\text {rd }}$} & 5 & $\begin{array}{l}\text { To revise the vocabulary of the thematic. } \\
\text { To correlate other words to the relevant } \\
\text { vocabulary. } \\
\text { To describe places of neighborhood in both } \\
\text { languages by creating Taboo cards. }\end{array}$ & Flexible grouping \\
\hline & 6 & $\begin{array}{l}\text { To complete three assignments related to } \\
\text { neighborhood. }\end{array}$ & Think-tac-toe \\
\hline \multirow[b]{2}{*}{$4^{\text {th }}$} & 7 & $\begin{array}{l}\text { To download a photograph of their hometown. } \\
\text { To set it as background in the Voki interface. } \\
\text { To create an avatar talking about hometown. }\end{array}$ & ICT tool (Voki) \\
\hline & 8 & $\begin{array}{l}\text { To pin their hometown on the map. } \\
\text { To upload a photograph in the pin. } \\
\text { To describe of hometown. } \\
\text { To draw lines connecting places on the map. }\end{array}$ & ICT tool (My Maps) \\
\hline
\end{tabular}




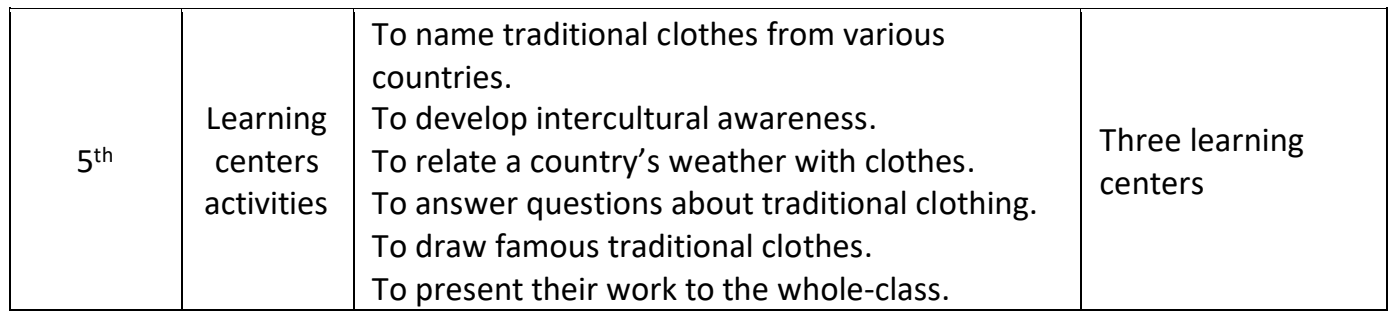

Table 3

Research cycles' learning objectives and differentiation strategies

\section{Participants}

Seven learners of migrant background participated in the research conducted in a RC operating within a public primary school of Agios loannis Rentis, in Piraeus. The particular primary school is in an urban, low-income area, with high rates of migrants as it is located near the Central Fruit Market of Athens, where many migrants work (about $30 \%$ of the pupils are of migrant background). Students' profiles are presented in Table 4. Due to anonymity issues, pseudonyms were appointed to students.

\begin{tabular}{|l|l|l|l|l|l|}
\hline Student's name & Gender & Age & $\begin{array}{l}\text { Country } \\
\text { of origin }\end{array}$ & Mother tongue & Enrolled in the RC \\
\hline Heba & Female & 11 & Egypt & Arabic & September 2017 \\
\hline Georgiana & Female & 11 & Romania & Romanian & February 2018 \\
\hline Gurlin & Female & 12 & India & Hindi/Punjabi & May 2018 \\
\hline Ali & Male & 11 & Egypt & Arabic & September 2017 \\
\hline Mohamed & Male & 10 & Egypt & Arabic & September 2017 \\
\hline Zahir & Male & 11 & India & Hindi/Punjabi & May 2018 \\
\hline Ekam & Male & 11 & India & Hindi/Punjabi & November 2017 \\
\hline
\end{tabular}

Table 4

Participant's profiles

Learners' educational needs were identified through assessment tests regarding their competence in Greek, designed by the Ministry of Education, Research and Religious Affairs and the Pedagogical Institute, which were conducted at the beginning of the school year. More precisely, due to students' different time of enrollment in the school, their different prior educational experiences, their competence in their mother tongue, as well as their socio-economic background, their literacy needs in the Greek language varied. Thus, although they all enrolled in the RC I ZEP (novice learners) according to the assessment tests conducted, some students were more advanced, as they attended supplementary private lessons in Greek during the afternoon, while others were facing difficulties that impeded their progress and a common pacing. Moreover, some were more competent in their first languages, as they attended courses in the afternoon (all the Egyptians), while others were starting to forget their mother tongues (e.g. not practicing writing skills in Punjabi anymore). According to the test scores and the observation throughout the school year, students' level of readiness in Greek before the implementation of the first cycle is shown in Table 5. However, readiness differs from competence, as it is not a fixed situation. On the contrary it varies, depending on the 
students' entry point to the instructional content. Thus, throughout the research cycles, students' readiness varied, depending on the content of instruction.

\begin{tabular}{|l|l|}
\hline Student's name & Level of readiness \\
\hline Heba & Low \\
\hline Georgiana & Low \\
\hline Gurlin & Low \\
\hline Ali & Medium \\
\hline Mohamed & High \\
\hline Zahir & Low \\
\hline Ekam & Low \\
\hline
\end{tabular}

Table 5

Students' level of readiness

\section{Data collection}

\section{Reflective diaries}

In order to answer the first research sub-question about the impact of DI combined with LAP on CLD students' engagement in the learning process, data derived mainly from the researcher's reflective diaries, as these are commonly used by teachers who conduct research (Altrichter, Feldman, Posch, \& Somekh, 2007). These diaries were written after the completion of each teaching intervention. In order to ensure credibility, each teaching intervention was recorded. Also, data from students' portfolio were used to enhance credibility (Johnson, 2012). In each research diary, the same structure was followed in order to facilitate data analysis. Firstly, each intervention was described, secondly, each student's reaction and engagement to the activities was noted. At the end of each diary entry, the researcher was reflecting on the intervention's outcome.

In order to enhance reliability, methodological triangulation of textual, visual or audio data deriving from students' work and textual data deriving from research diaries was conducted (Cohen, Manion, \& Morrison, 2018). Namely, data included photographs of students' notebooks, worksheets, drawings and handcrafts, screenshots of the digital environments they engaged, as well as audio data from their engagement in oral activities.

\section{Focus group discussion}

In order to answer the second research sub-question about students' perceptions on the new practice, the researcher conducted a focus group discussion after the completion of all research cycles. Drawing on the transformative nature of this research and on Gibson's (2012, p. 150) words about how "children have moved from the margins, to be seen as partners in the research process", conducting a focus group discussion seemed the most suitable research tool in order to investigate student's perceptions. Focus group discussion was preferred rather than individual interviews, due to the opportunity it offers for a more comfortable discussion, facilitating introverted students to participate without anxiety. 
The discussion lasted about 25 minutes, it was conducted in the RC with all students and it was recorded and transcribed, in order to be analyzed via content analysis. The discussion was oriented towards the following themes:

- students' feelings about the use of their home languages in the classroom

- students' perceptions of language and intercultural awareness promoted by the activities

- students' feelings about using multiple materials and activities in the context of DI

- students' experiences in their mainstream classes

\section{Data analysis}

Content analysis was applied to the data deriving from the researcher's diaries and the transcribed text of the focus group discussion. Content analysis was used as it is a flexible, systematic and rigorous approach for synthesizing a wide range of data (White \& Marsh, 2006). Themes or patterns were interpreted in narrative passages and subquestions were answered. In order to enhance reliability so as to answer the main research question about the use of DI combined with LAP, findings from the researcher's experience in the classroom as well as from the participants' perceptions on it, were synthesized.

More precisely, from the content analysis of the diary data the relevant to students' engagement themes that emerged were:

- students' motivation

- students' relationships

- reaction to DI combined with LAP

Similarly, the following themes emerged from the data analysis of the focus group discussion about students' perceptions of:

- the varying materials and assignments

- the use of students' mother tongues

- language awareness

- intercultural awareness

- the practices used in the mainstream classes

\section{Results}

\section{First research cycle outcomes}

\section{Activities implementation}

During the first cycle, all students participated in the Activities 1 and 2 while three students (Gurlin, Mohamed and Ali) were urged to engage in the thick-tac-toe activity, as they finished their work earlier. Concerning Activity 1 , students' products are presented in Table 6 and examples of their work are presented in Figures 1,2 and 3. 


\begin{tabular}{|l|l|l|}
\hline Level of readiness & Students' names & Assignment \\
\hline Low & $\begin{array}{l}\text { Gurlin } \\
\text { Ekam } \\
\text { Georgiana } \\
\text { Heba }\end{array}$ & Poster creation in both languages \\
\hline Medium & Ali & Recipe card in both languages \\
\hline High & Mohamed & $\begin{array}{l}\text { Shopping list in both languages and } \\
\text { role-playing }\end{array}$ \\
\hline
\end{tabular}

Table 6

Students' products according to their level of readiness

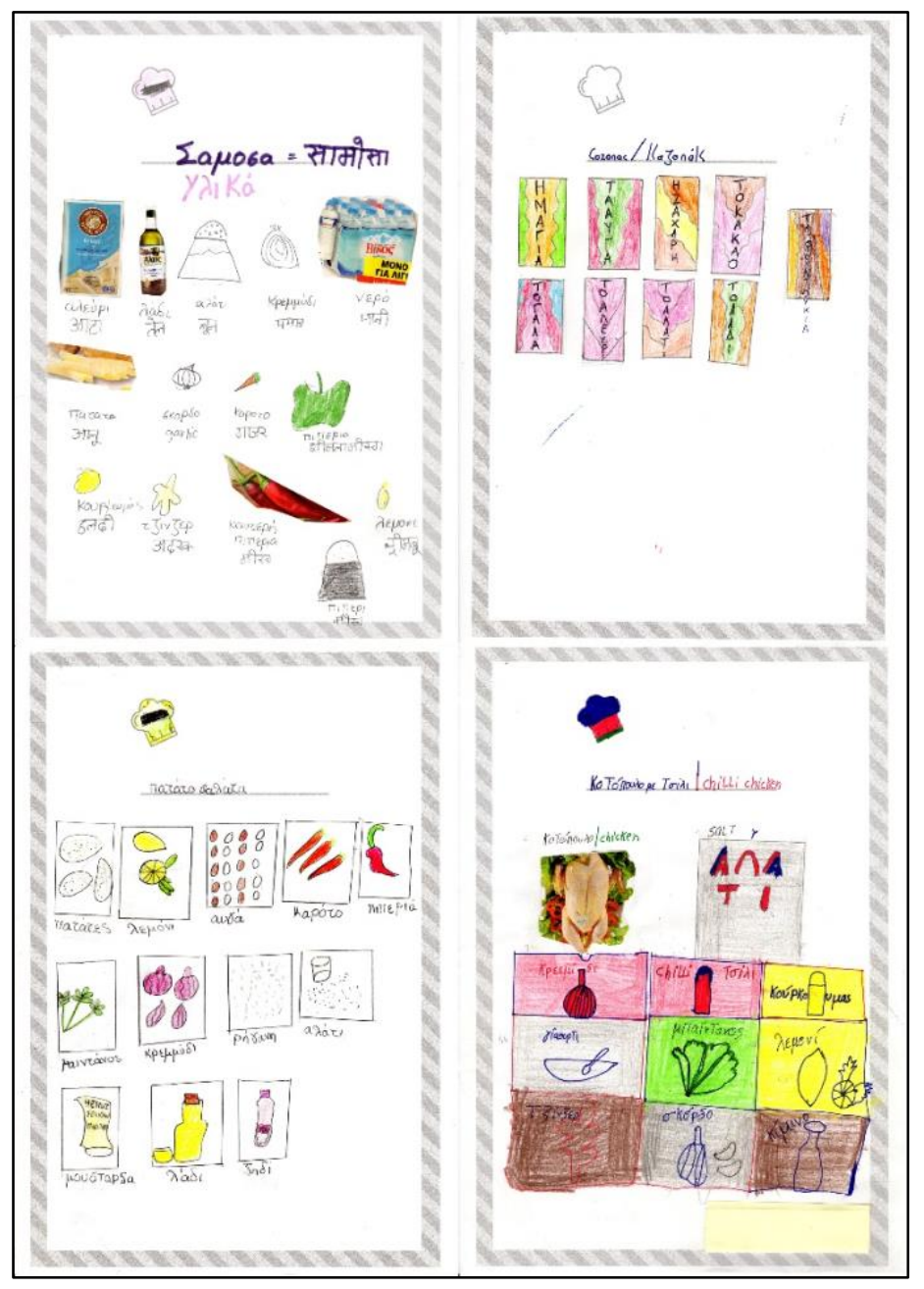

Figure 1

Poster creation 


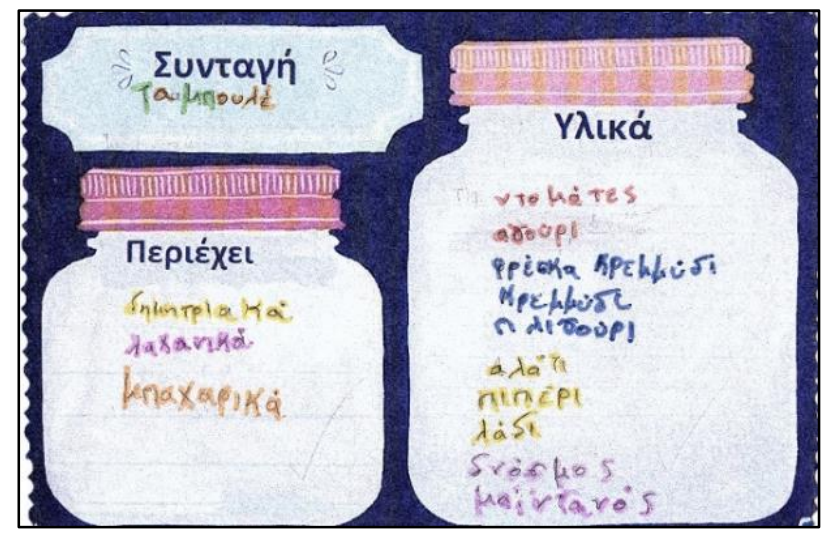

Figure 2

Recipe card

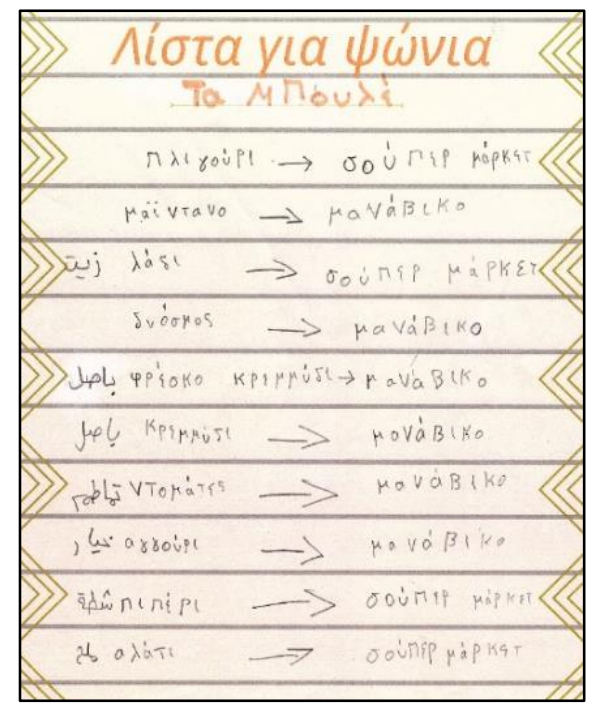

Figure 3

Shopping list

Moreover, the think-tac-toe anchor activity that was used due to students' different times of activities completion is presented in Figure 4. Three students engaged in it, and only one of them (Gurlin) completed a combination of three activities (assignments 4, 5, 6). 


\begin{tabular}{|c|c|c|}
\hline 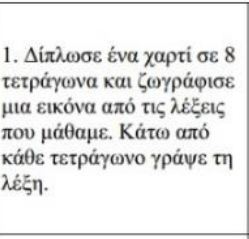 & 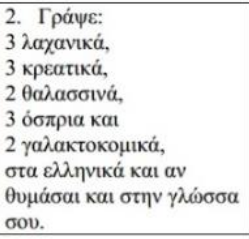 & 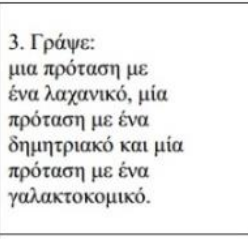 \\
\hline 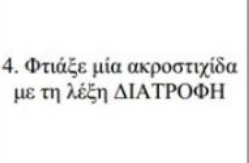 & 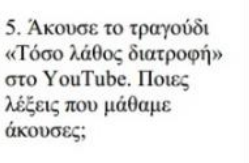 & 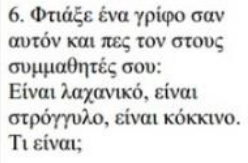 \\
\hline 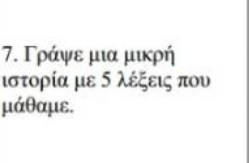 & 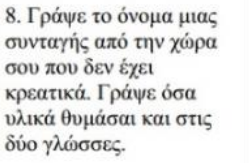 & 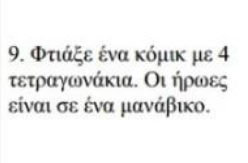 \\
\hline
\end{tabular}

Figure 4

Anchor activity - Think-tac-toe

In Activity 2, a tiered activity, a transnational menu was created by students in two teams depending on their level of readiness. More precisely, two students of lower level of readiness (Georgiana and Heba) wrote in the menu the name of the given recipes and their origin, as well as the number of their ingredients. Five students of higher level of readiness categorized the given recipes into the kinds of dishes, wrote the name of the recipes and their origin, the number of the ingredients and the basic categories of food they contained (Figure 5).

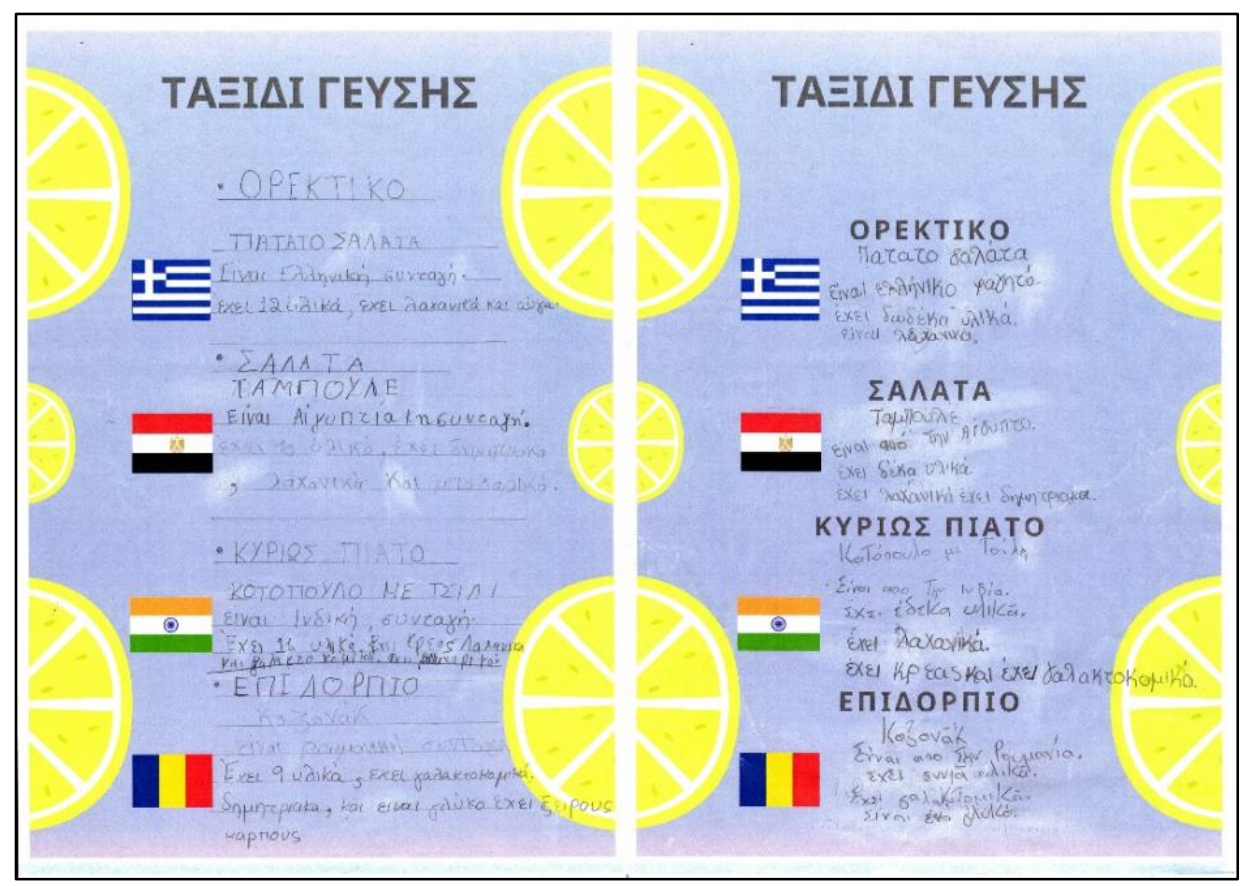

Figure 5

Transnational menu of lower and higher level of readiness 
The outcomes of this cycle were organized in themes according to content analysis that was applied to the diary data. The relevant themes to students' engagement that emerged from the careful reading of the diaries are presented below.

\section{Students' motivation}

All students were motivated to engage in Activities 1 and 2. Those who finished their work earlier were eager to choose from the think-tac-toe anchor activity, however, only Gurlin was more enthusiastic and managed to complete the three assignments. When she was thinking of the activities, in order to select three of them she said: "I don't want easy because I'm going to the [u $\mu v \alpha$ o'o [high school] and I want to remember all the

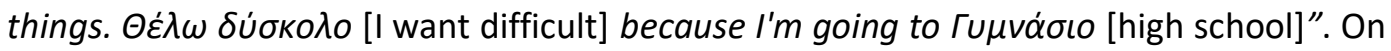
the other hand, Mohamed and Ali chose the same combination of assignments. Mohamed finished two assignments (Figure 6). Ali didn't find all the words of assignment 5, he felt frustrated and stopped trying to complete the rest two assignments. He sat on his own in a desk and refused to finish the work although the researcher tried to convince him to continue.

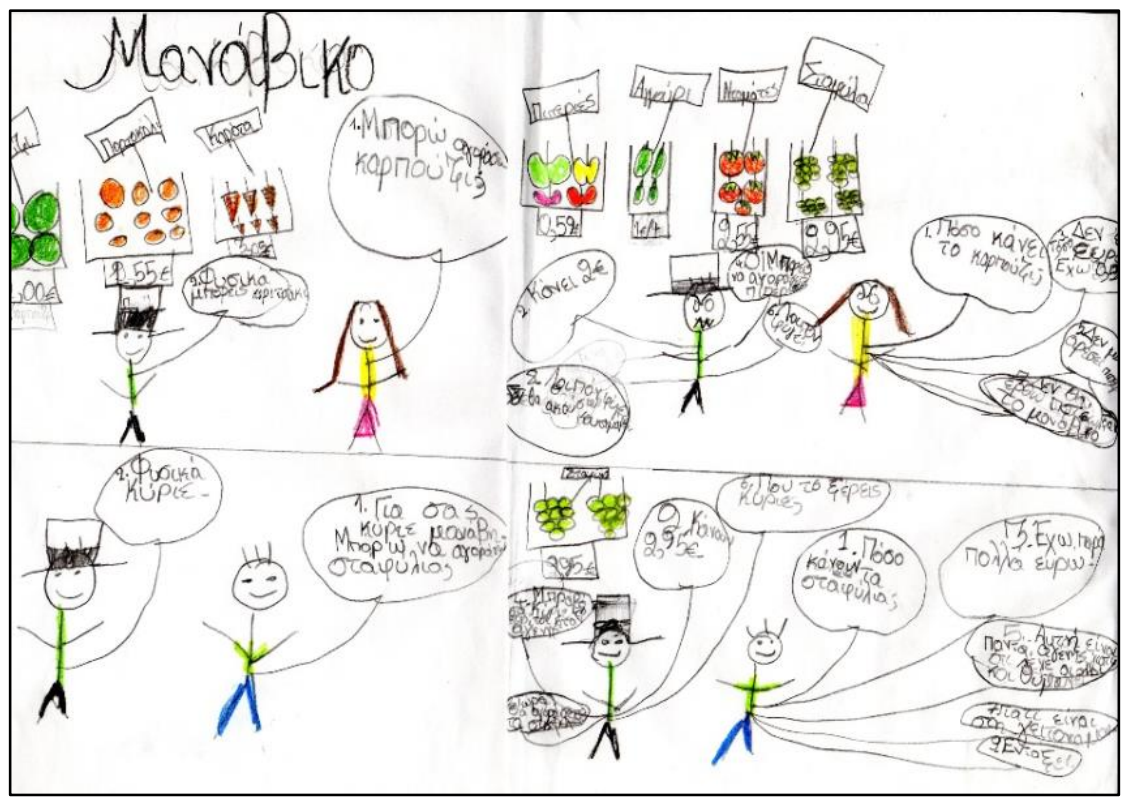

Figure 6

Think-tac-toe anchor activity-assignment 9

Students' increased motivation was obvious after the first activity lesson by the fact that they did not leave the classroom immediately but they were staring at each other's work which was hanging on the wall. Moreover, Gurlin said while leaving: "Kupia,

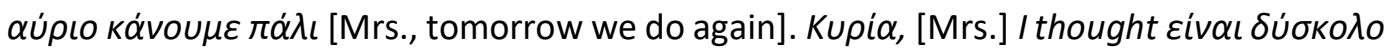
$\alpha \lambda \lambda \dot{\alpha} \delta \varepsilon v$ cival [it is difficult but it's not]."

Activity 2 was completed in three teams, within two hours. Students were motivated by the fact that the menu contained dishes from their countries. Motivation, however, was increased when they performed the role-play in two teams. When the

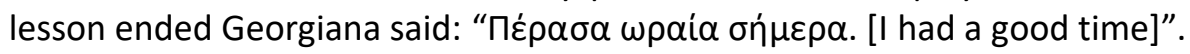




\section{Students' relationships}

Concerning students' relationship, there were times of tension between students (mostly between Georgiana and Ekam). The researcher writes in her diary: "The varying pacing is also due to the bad relationships between them. Valuable time is lost when something's happening between them". That was noticed during the third hour of the intervention as students entered the classroom in a bad mood. Valuable time was lost, as the researcher interrupted many times the whole-class instruction, in order to ensure good learning conditions. Thus, the researcher noticed that the activities did not improve their current relationship.

\section{Reaction to Differentiated Instruction blended with Linguistically Appropriate Practice}

Although it was students' first contact with DI and they were not acquainted with the nature of the differentiated lesson, there were only a few moments of negation on students' behalf. A student expressed a question about the lesson process. She asked:

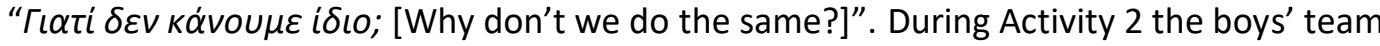
expressed fears that girls' team would finish sooner as they had to complete an easier assignment. However, these concerns were expected and they were not a deterrent against engaging in the activities.

Moreover, although they were prompted to use their first languages in the assignments, only two students accomplished to use their first language (Arabic and Punjabi) in Activity 1. Additionally, none of the students who engaged in think-tac-toe activity chose the assignments which integrated their home languages.

\section{Reflection on the outcomes of the first cycle}

In general, the first research cycle was completed successfully as all learners engaged in a variety of activities. In terms of activity choice in think-tac-toe, two students selected the same combination, a fact that concerned the researcher as students tended to get influenced by the choices of their classmates. This was the case of Ali who felt frustrated by a listening activity and never completed the remaining activities of the thinktac-toe. Moreover, the most advanced student said that he didn't want to choose the writing activities. This problematized the researcher who reflected on it: "They face difficulties with writing and I have to use a differentiation technique for it. They never do these kinds of activities with pleasure".

Concerning students' relationships, there was a slight improvement, however, there were still times of tension which impeded students' full engagement and total concentration on the learning objectives. This preoccupied the researcher who reflected on the way the next activities should be designed in order to ensure a good classroom environment.

\section{Second research cycle outcomes}

\section{Activities implementation}

The activities of this cycle aimed at engaging learners in writing, to enhance their oral skills and to ensure a pleasant classroom environment in order to avoid tensions. The RAFT strategy in Activity 3 was selected, as it is suitable for differentiated lessons and gives the opportunity for students to engage in writing activities through creative thinking 
and writing. Additionally, RAFT aimed at eliminating students' negation to engage in writing activities, a problem that was identified during the first research cycle. Moreover, Activity 4 entailed collaboration and role-playing in order to ameliorate students' bad relationships and facilitate engagement in the learning process. Thus, in Table 7, students' engagement in the Activity 3, based on the RAFT strategy is presented.

\begin{tabular}{|l|l|l|l|l|}
\hline Student & Role & Audience & Format & Topic \\
\hline Gurlin & Advertiser & Consumers & Advertisement & Advertise a sweet \\
\hline Heba & Daughter & Mother & SMS & $\begin{array}{l}\text { Send an SMS to } \\
\text { your mother to ask } \\
\text { her about a recipe }\end{array}$ \\
\hline Georgiana & Advertiser & Consumers & Advertisement & Advertise a sweet \\
\hline Zahir & Chef & Viewers & $\begin{array}{l}\text { Recipe card for } \\
\text { TV show }\end{array}$ & Present a recipe \\
\hline Ekam & $\begin{array}{l}\text { Chef/comics } \\
\text { creator }\end{array}$ & Viewers/Readers & $\begin{array}{l}\text { Recipe card for } \\
\text { TV show/ comic }\end{array}$ & $\begin{array}{l}\text { Present a } \\
\text { recipe/create a } \\
\text { comic in a } \\
\text { restaurant }\end{array}$ \\
\hline Ali & Journalist & $\begin{array}{l}\text { Newspaper } \\
\text { readers }\end{array}$ & Article & $\begin{array}{l}\text { Write an article } \\
\text { about a recipe }\end{array}$ \\
\hline Mohamed & Chef & Viewers & $\begin{array}{l}\text { Recipe card for } \\
\text { TV show }\end{array}$ & Present a recipe \\
\hline
\end{tabular}

Table 7

Students' choice (RAFT strategy)

Moreover, for the purposes of Activity 4 the researcher distributed three menus with dishes from many countries and students were separated into three teams. Each team had a menu which was read aloud in sequence. Then, the researcher urged each team to select from the menu they preferred, dishes from each category. Thus, depending on students' interests, differentiation of content was achieved. Subsequently, in teams they performed a roleplay in a restaurant. The teams that were formed were the following: Ekam-Georgiana, Zahir-Heba and Gurlin-Ali. The criteria for forming the pairs were students' nationality (different ones) and their relationship (tried to match students with conflicts). They all managed to collaborate and carry through with the activity.

\section{Students' motivation}

During the RAFT activity, the majority of students responded positively, except Ali and Heba who faced difficulties with choosing a role and producing written text. Presenting their product at the end of the two-hour lesson, was also motivating except Ali who did not want to present his work as a journalist, neither to self-correct his assignment and this was interpreted as a sign of frustration about his assignment.

More precisely, Ali changed his mind many times about the role and lost valuable time. During the first hour of the intervention, he wrote only the name of the recipe as an article title (Figure 7). Also, Heba was reluctant and was constantly asking for help. She was discouraged when she was watching the other students engaging in their activities and teared her paper by accident (Figure 8). Although the researcher tried to suggest other roles, she said: " $\Delta \varepsilon v \mu \pi о \rho \omega \dot{~[I ~ c a n ' t] " . ~ F i n a l l y, ~ s h e ~ c o m p l e t e d ~ t h e ~ a s s i g n m e n t ~ w i t h ~}$ Georgiana's help, as the latter was the first finishing her assignment. On the other hand, 
Georgiana was the only student who completed the writing activity during the first hour of the intervention (Figure 9). Although she made mistakes, she was absorbed by the assignment and did not disturb anyone. The researcher writes in her diary: "it was the first time that Georgiana wrote a text without asking me what to write and without interrupting the learning process". Moreover, the fact that she was the first who completed the assignment, made her feel more confident and tried to help Heba.

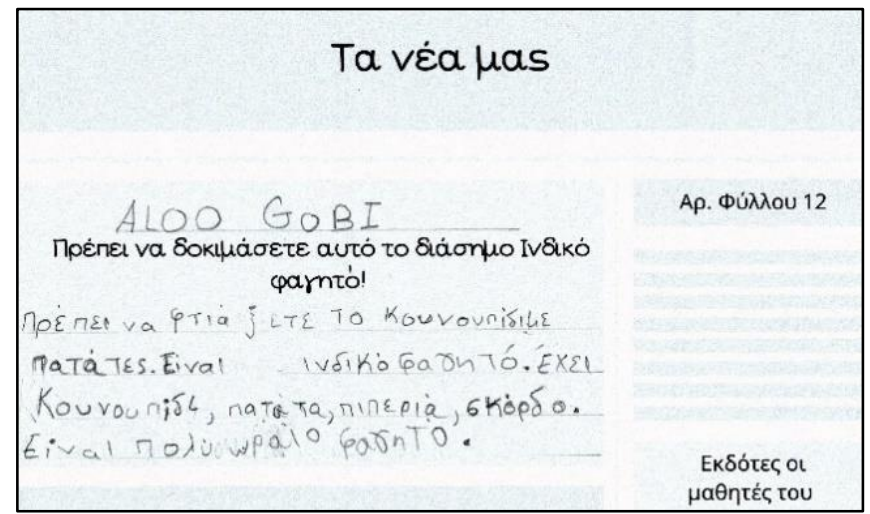

Figure 7

Article produced by Ali

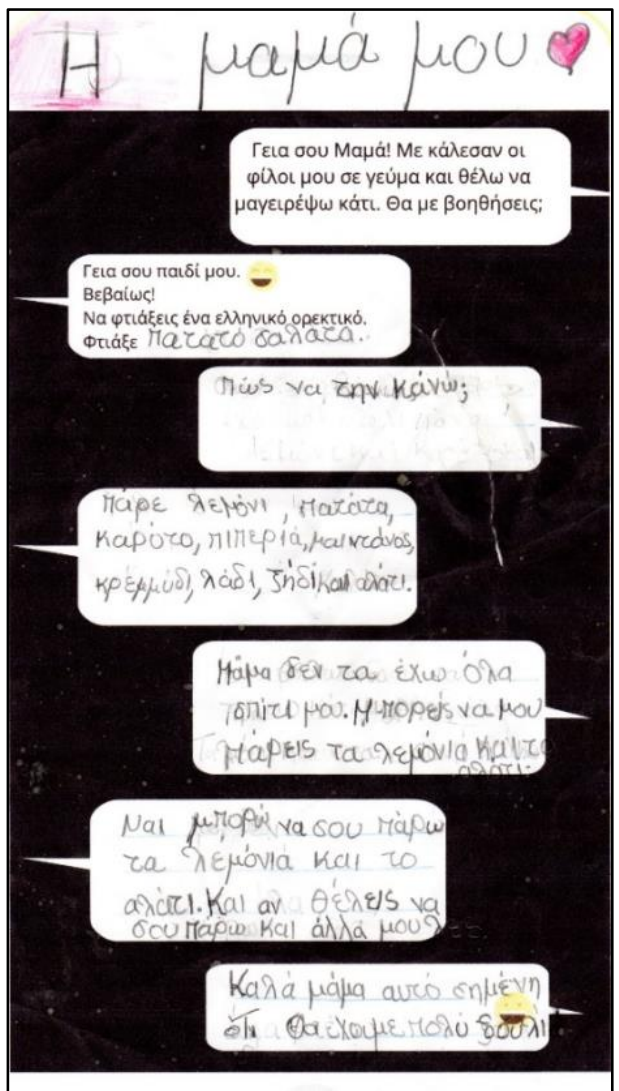

Figure 8

SMS produced by Heba 


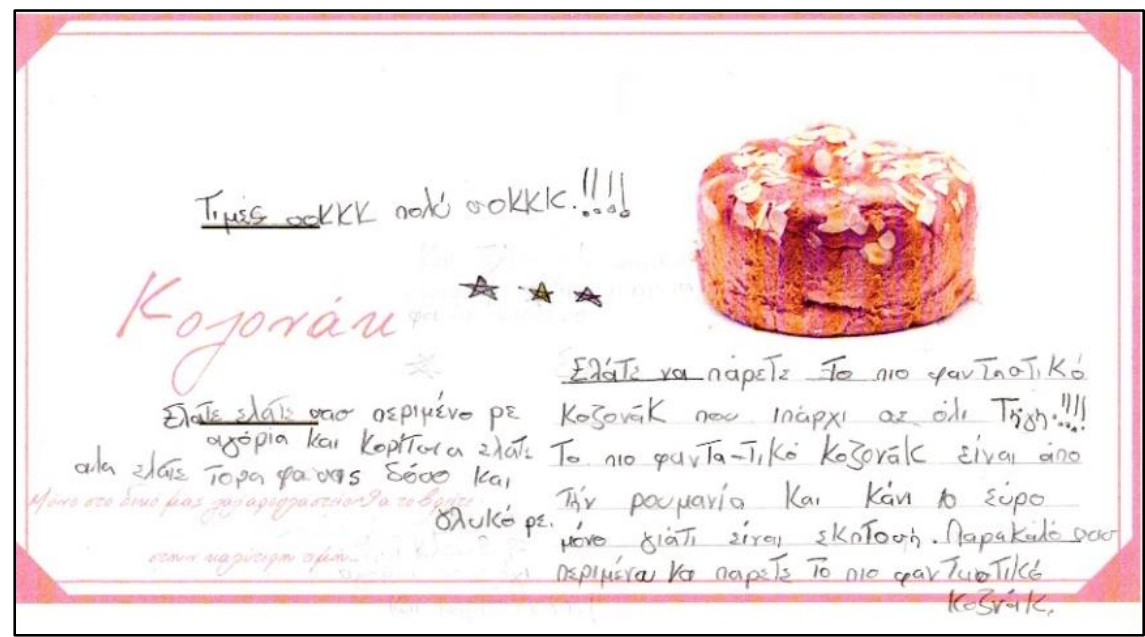

Figure 9

Advertisement produced by Georgiana

Regarding the other students, Ekam expressed his will to engage in two roles, a fact that was interpreted by the researcher as a sign of increased motivation (Figures 10, 11), while Mohamed's role as a chef was to present an Indian recipe card which he accomplished easily (Figure 12). Finally, the self-correction rubric was motivating for Zahir and Gurlin who tried to improve the look of their assignment and checked again for spelling and intonation mistakes (Figures 13,14).

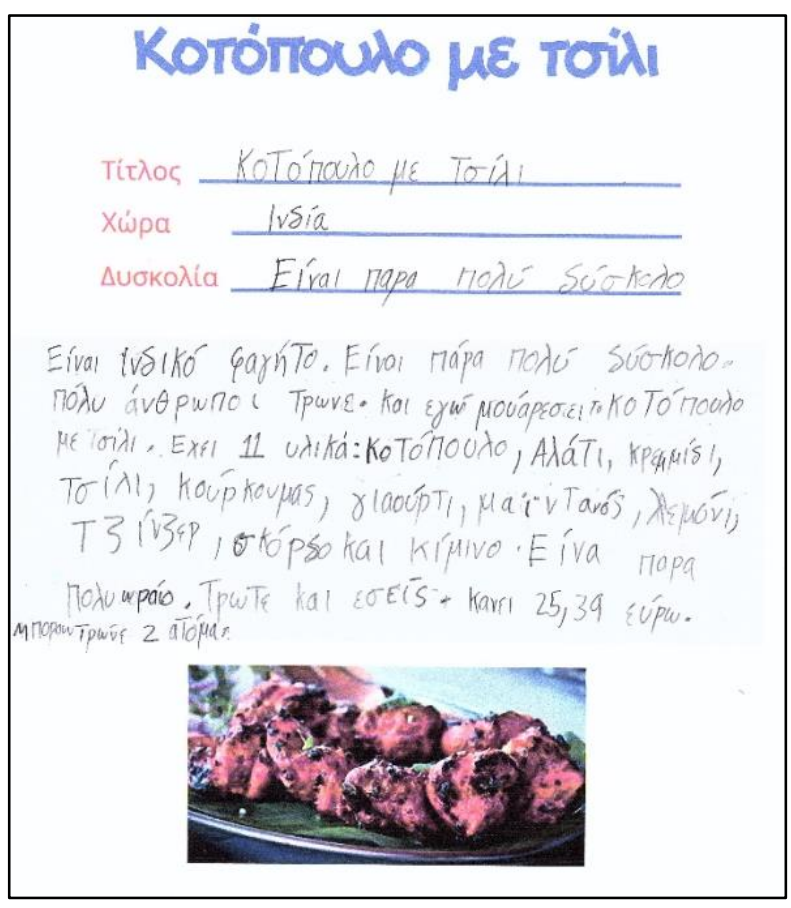

Figure 10

Recipe card for TV-show produced by Ekam 


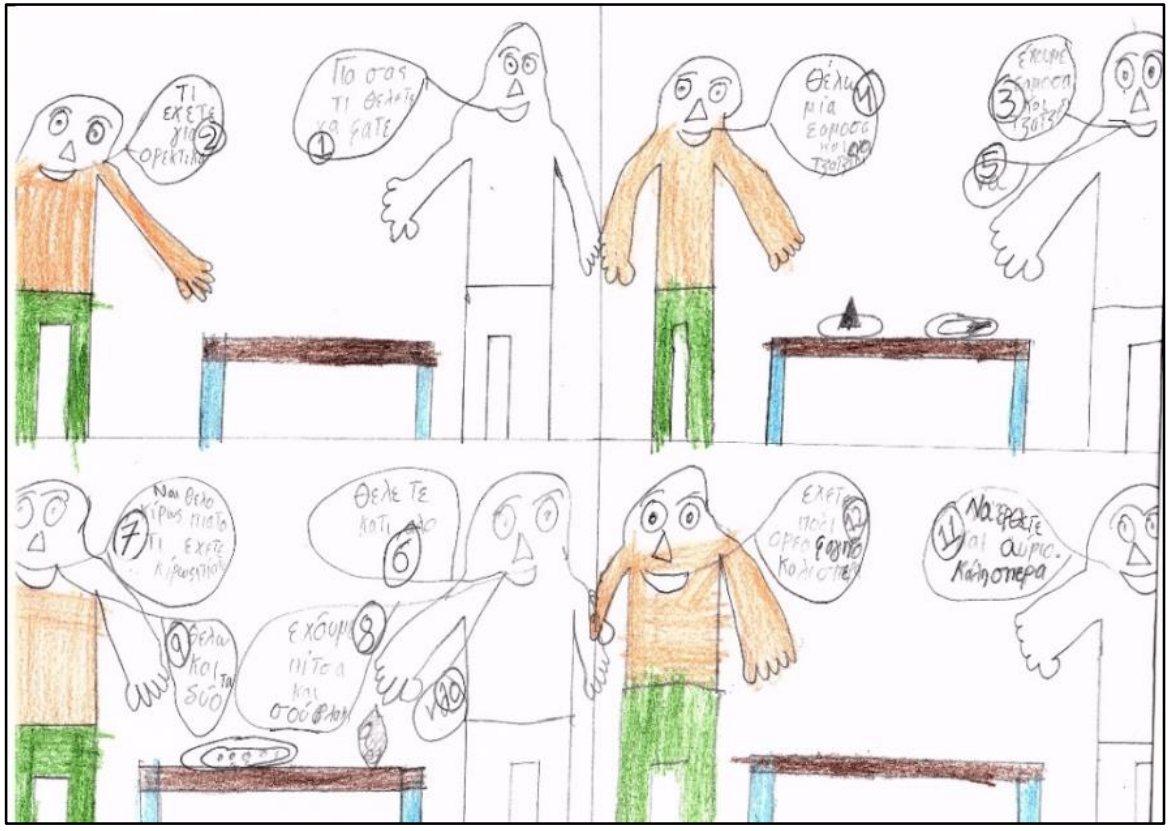

Figure 11

Comic in a restaurant produced by Ekam

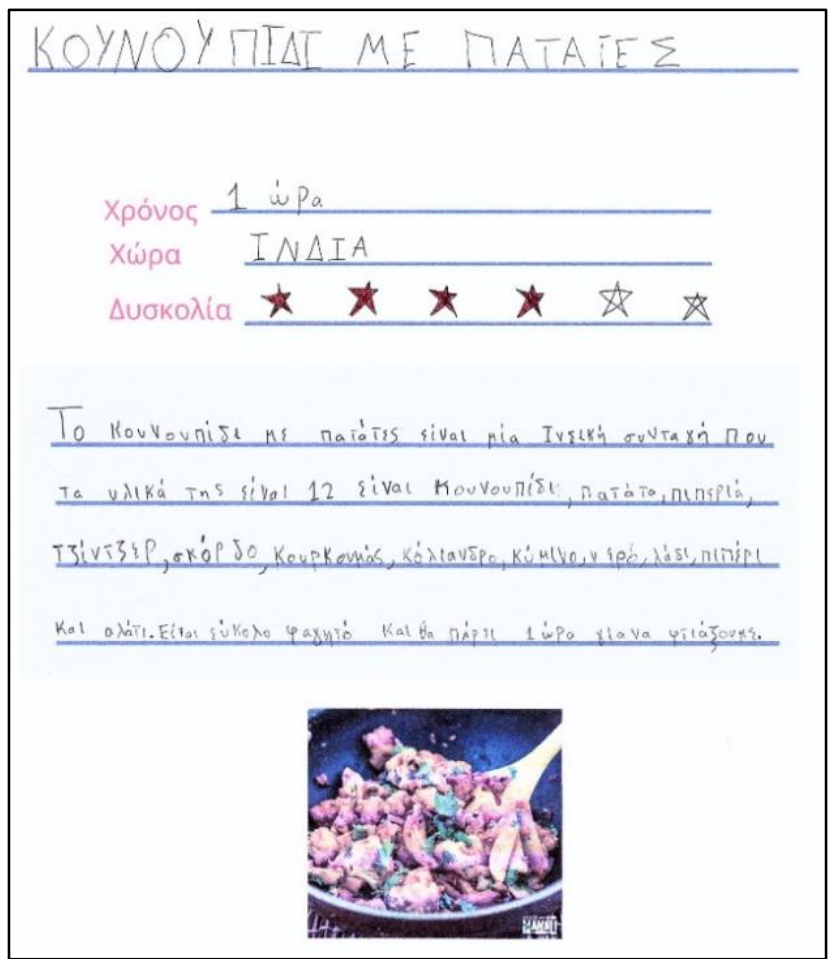

Figure 12

Recipe card for TV-show produced by Mohamed 


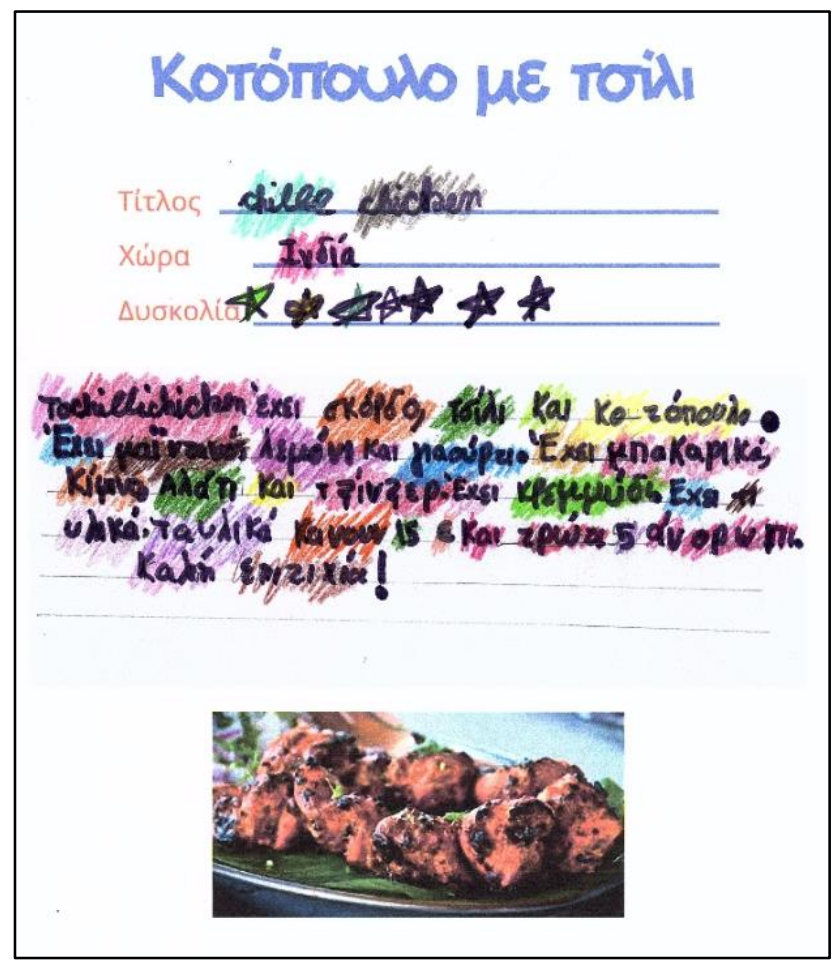

Figure 13

Recipe card for TV-show produced by Zahir

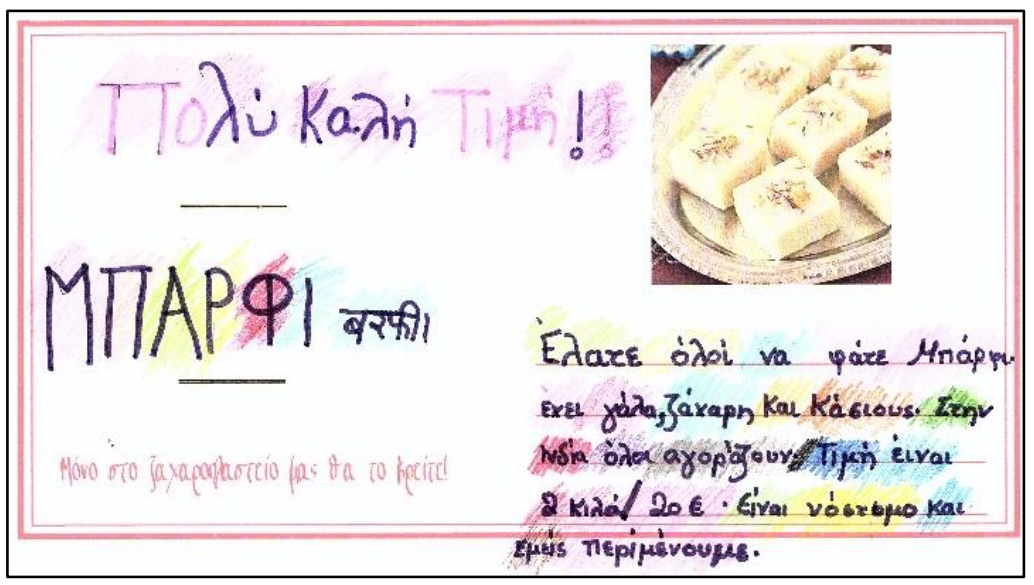

Figure 14

Advertisement produced by Gurlin

Related to Activity 4, all students were keen on performing roleplays, thus they all participated in the activity. This was noticed by the researcher who reflected: "They like pretending roles and surprisingly they accepted the pairs' formation relatively smoothly meaning that heterogeneous grouping did not seem to be a real problem". 


\section{Students' relationships}

During the RAFT activity, the majority of students and especially Georgiana and Ekam, totally engaged in their assignments and did not provoke any tension during the lesson. Their improved relationship was reflected on Georgiana's praising words about

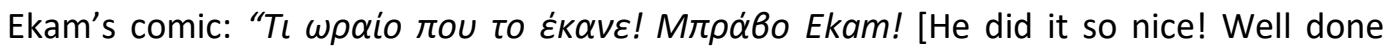
Ekam!]". Moreover, it was noticed that Georgiana, in her free time, voluntarily helped Heba with her assignment, a fact that was interpreted as a sign of increased empathy and support on her behalf.

Also, students' collaboration was successful in Activity 4, even though it was precarious, as the pairs' formation was risky. Their motivation to participate in roleplaying was stronger than their doubts to collaborate with each other. There were only a few complaints that were overcome easily. Especially Georgiana and Ekam collaborated successfully and this was proved by Ekam's reaction after their role-playing: "Georgiana, hi five!". All in all, during the second cycle students' relationships improved noticeably.

\section{Reaction to Differentiated Instruction blended with Linguistically Appropriate Practice}

Unlike the first cycle, students did not express any question about the fact that many of them engaged in different assignments. However, different assignments might have impacted negatively on the two students facing difficulties, as they felt frustrated when watching their classmates proceeding. This was evident when Heba commented that her assignment was more difficult. Even so, she did not alter her choice about the assignment, as urged by the researcher.

Concerning the integration of foods which come from students' countries in the assignments, this was positively perceived by students and affected their motivation. Moreover, students did not seem to react negatively when engaging in assignments entailing foods from other countries. On the contrary, although the researcher doubted that Mohamed would engage in an assignment entailing the description of an Indian

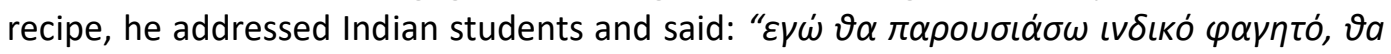

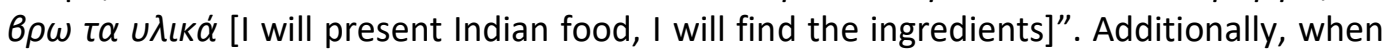
Georgiana in role-playing chose for dessert the Indian Barfi, Gurlin praised her by saying:

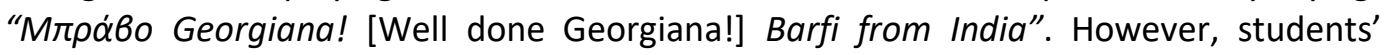
languages were not used in most of the activities, except Zahir's presentation as a chef, when the researcher urged him to present his recipe in Punjabi, as he was having difficulties in Greek.

\section{Reflection on the outcomes of the second research cycle}

The learning objectives of this research cycle were in general satisfied, as the majority of students engaged in the writing activities without complaining, as in the past, when assigned to produce a text. RAFT strategy helped students to engage creatively in writing and practice their oral skills, giving them freely the chance to choose, among various roles. However, students less competent in writing, needed more scaffolding by the researcher, as they soon felt frustrated.

Furthermore, activity 4, which was more experiential, was more motivating for all students. This made the researcher reflect on the design of the third cycle: "I have to 
integrate more experiential activities because these seem to motivate students. Especially the next thematic of Neighborhood is suitable for these kinds of activities". Another aspect that was taken into consideration about the next thematic was the more active integration of students' mother tongues during the learning process as the researcher writes: "I have to integrate students" languages more, because so far, my orientation was to integrate their different cultural backgrounds in the learning process, rather than their languages."

\section{Third research cycle}

\section{Activities implementation}

In this cycle, the thematic unit of Neighborhood was introduced. Activity 5 was a task where students created a 'Taboo' game. Thus, five kinds of card decks of a different color were created by students. In order to differentiate instruction, students of a higher level of readiness were assigned to create a 'difficult' card deck (pink), with five forbidden words that describe the target-word, while those of a lower level of readiness created an 'easy' card deck (yellow), with three forbidden words. Subsequently, in teams consisting of speakers of the same mother tongue, students created three more card decks (green in Punjabi, red in Arabic and blue in Romanian) with no restriction about the number of words to be written (Figure 15). In Table 8 students' engagement in the cards decks is presented:

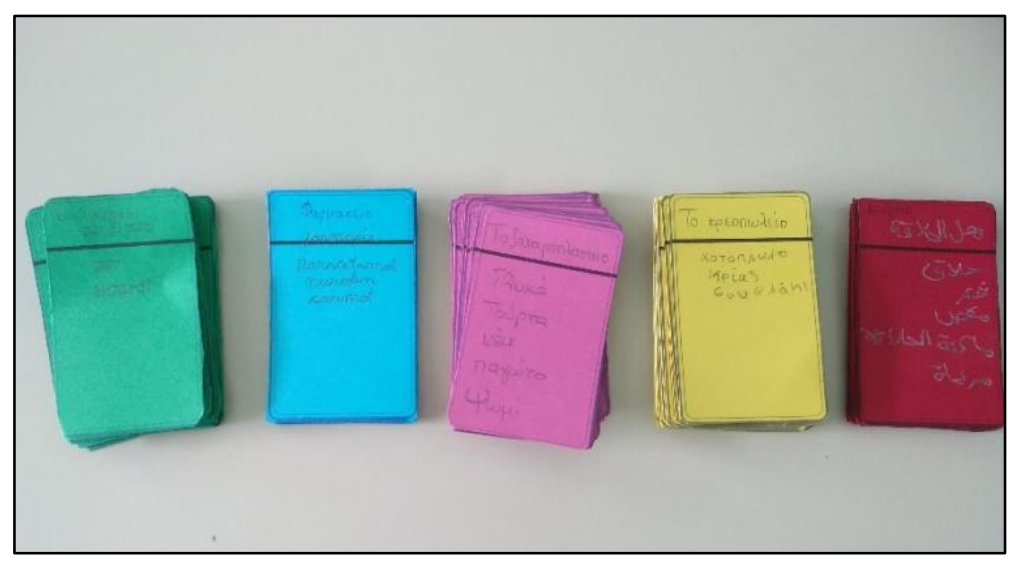

Figure 15

Taboo five card decks

\begin{tabular}{|l|l|}
\hline Card deck & Students' name \\
\hline \multirow{3}{*}{ Pink } & Mohamed \\
& Zahir \\
& Ekam \\
& Gurlin \\
\hline \multirow{3}{*}{ Yellow } & Ali \\
& Heba \\
& Georgiana \\
\hline
\end{tabular}




\begin{tabular}{|l|l|}
\hline Green & $\begin{array}{l}\text { Zahir } \\
\text { Ekam } \\
\text { Gurlin }\end{array}$ \\
\hline \multirow{2}{*}{ Red } & Ali \\
& $\begin{array}{l}\text { Mohamed } \\
\text { Heba }\end{array}$ \\
\hline Blue & Georgiana \\
\hline
\end{tabular}

Table 8

Students'engagement in Taboo card decks

In Activity 6 (Figure 16), students were expected to choose three assignments scoring a think-tac-toe, related to Neighborhood. Initially, the researcher was adamant that students ought to score a think-tac-toe, but consequently she reflected on the possibility of being more flexible in case students could not score a think-tac-toe. Hence, students were urged to complete three activities without the restriction of think-tac-toe scoring. Students showed through various ways their knowledge about Neighborhood. In Table 9 students' choices and think-tac-toe scoring are presented.

\begin{tabular}{|c|c|c|}
\hline 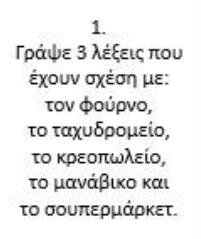 & 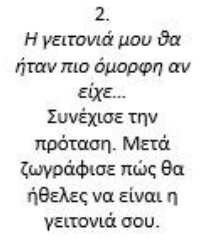 & 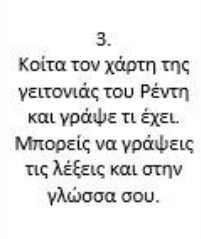 \\
\hline 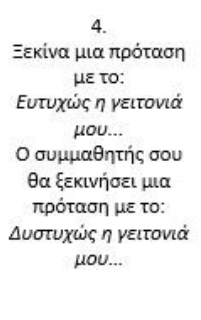 & 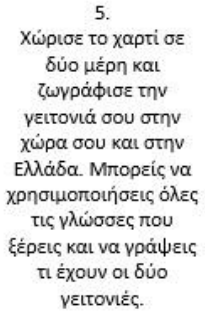 & 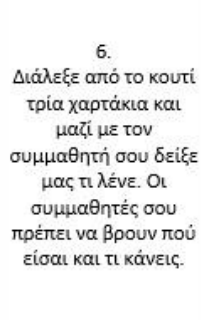 \\
\hline 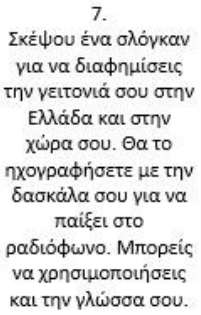 & 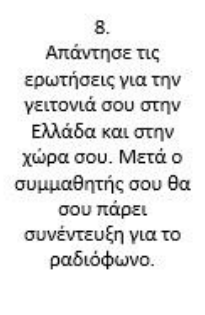 & 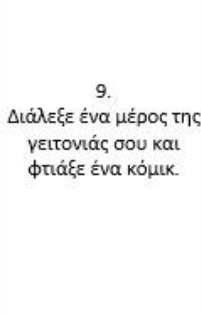 \\
\hline
\end{tabular}

Figure 16

Neighborhood Think-tac-toe 


\begin{tabular}{|l|l|c|}
\hline Student & Activities chosen & Scored a 'think-tac-toe' \\
\hline Gurlin & $3,6,7$ & \\
\hline Heba & $3,5,7$ & $\square$ \\
\hline Georgiana & $3,5,7$ & $\square$ \\
\hline Zahir & $3,6,7$ & \\
\hline Ekam & $3,6,9$ & $\square$ \\
\hline Ali & $7,8,9$ & $\square$ \\
\hline Mohamed & $7,8,4$ & \\
\hline
\end{tabular}

Table 9

Students' choices in Think-tac-toe

\section{Students' motivation}

All students were motivated by the playful nature of Activity 5. None complained, even those engaged in the difficult cards, which had extra workload, as they were excited about preparing the cards for the game. When assigned to create cards in their mother

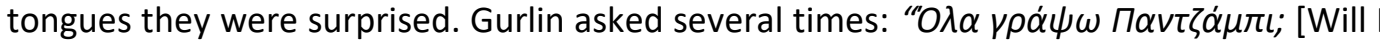
write everything in Punjabi?]". Heba and Ali were enthusiastic about using Arabic and

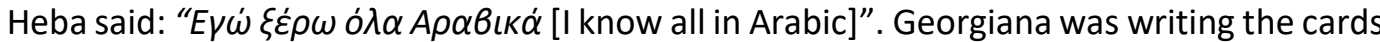
in Romanian in slow pacing and asked the researcher if she could take the cards at home to complete them since there was limited time. This was perceived as a sign of increased motivation.

In the think-tac-toe activity, although all students engaged in three assignments, four of them scored a think-tac-toe. Ekam filled in a worksheet about his neighborhood and created a comic (Figure 17). He was concentrated in the activity and he didn't ask for any help. Moreover, his participation in assignment 6 , which entailed role-playing, was motivating for him and formed a team with Zahir and Gurlin who chose also this assignment. Heba and Georgiana chose the same activities, although the latter, while

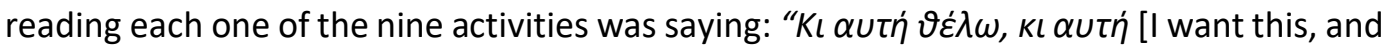
this]", showing her motivation. Additionally, both girls wrote and recorded a slogan in Greek about their neighborhood in Agios loannis Rentis. Georgiana's slogan, although it had a deficiency in meaning, was a result of multiple efforts. Heba created her slogan without requesting any help and pinned it on the announcement board, a sign of increased confidence. Ali also scored a think-tac-toe, however, his engagement in the comic creation was rather rushed (Figure 18). This was interpreted by the researcher as an effort to score a think-tac-toe, without really enjoying all three activities. 


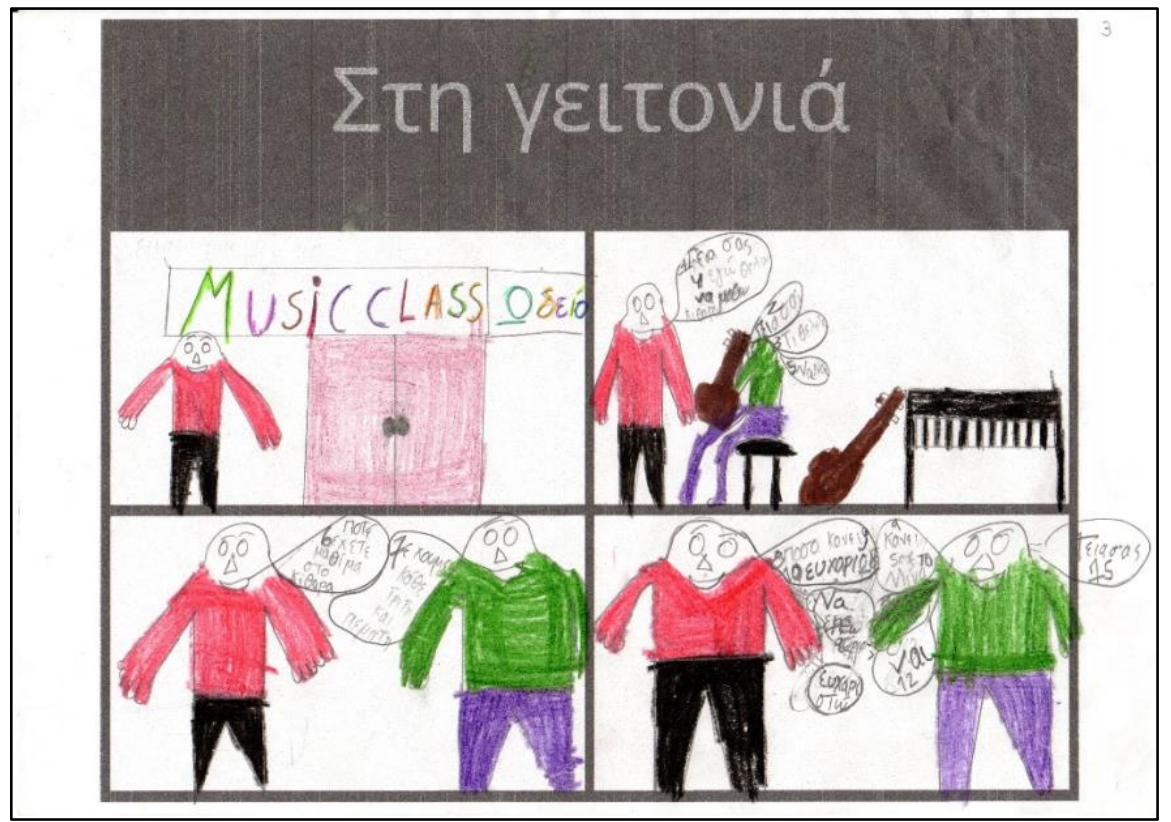

Figure 17

Neighborhood think-tac-toe (Ekam)

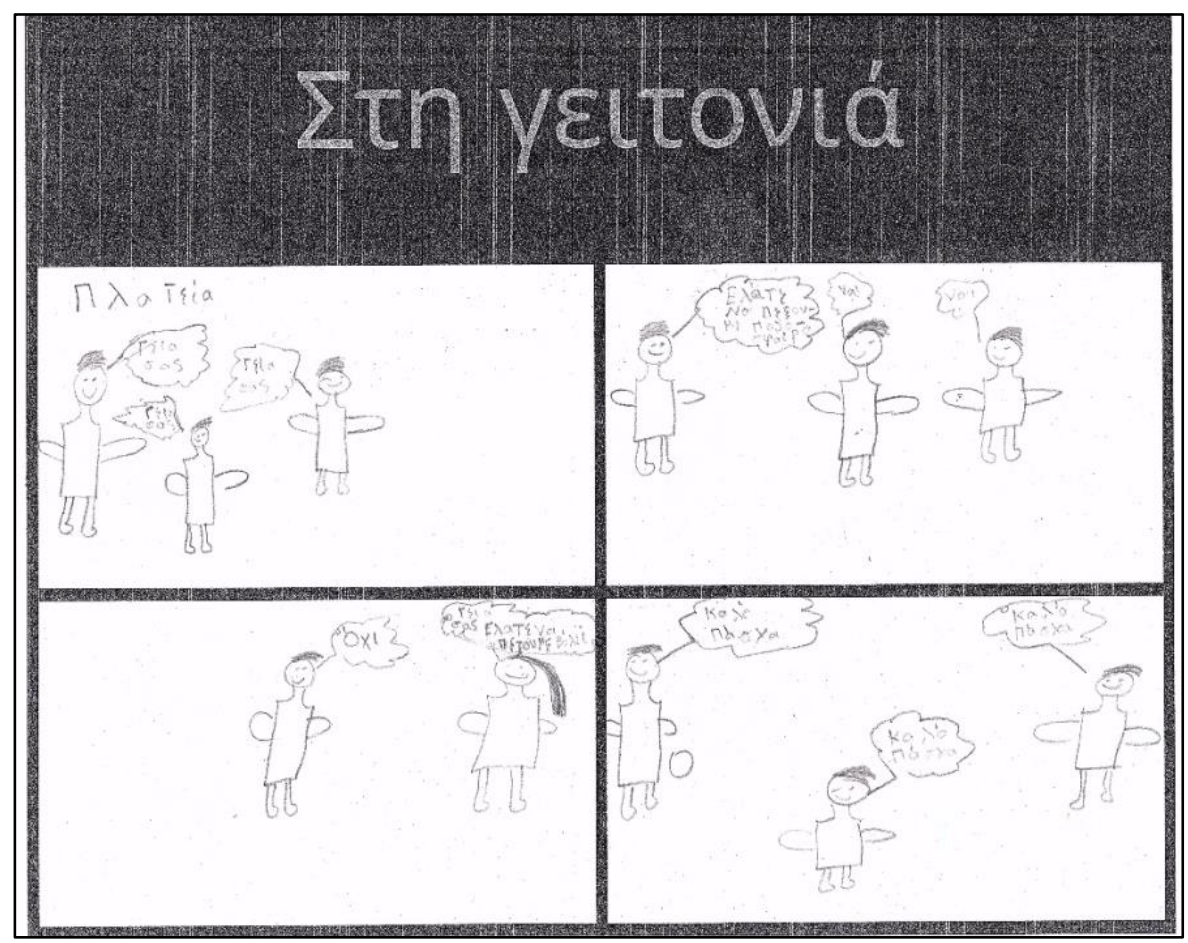

Figure 18

Neighborhood think-tac-toe (Ali) 
On the other hand, Zahir said that he didn't want to engage in the think-tac-toe

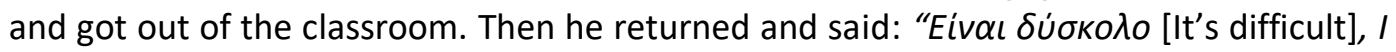
want to play in Quizlet", meaning that he could not score a think-tac-toe. The researcher helped him to choose three activities, whichever he preferred. Gurlin chose the same combination of activities with Zahir, as she desired to create a slogan about her neighborhood. However, she was not confident and said: " $\Delta \varepsilon v \xi \varepsilon \dot{\varepsilon} \rho \omega \pi \dot{\omega} \varsigma \kappa \dot{\alpha} v \omega[$ [ don't know how to make it]". Thus, scaffolding was necessary. Mohamed completed the activities but did not score a think-tac-toe, as he did not want to create a comic.

\section{Students' relationship}

Due to the flexible grouping of Activity 5, many teams were formed. In the beginning students of the same level of readiness cooperated, while afterwards, students of the same mother-tongue. Finally, students played Taboo forming various groups. No tensions were noticed during playing. Concerning Activity 6, Gurlin and Zahir, who chose the slogan assignment, collaborated successfully, in order to record a slogan about their neighborhoods in Greece and in India in a rap style. Their slogan in Greek was:

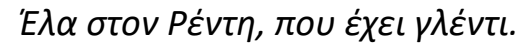

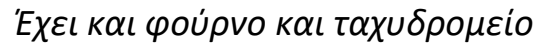

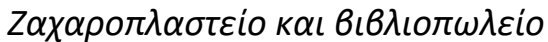

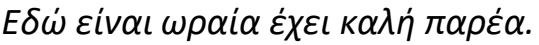

Moreover, Ali and Mohamed were also a team for the slogan creation about Agios loannis Rentis. Their cooperation resulted in this slogan:

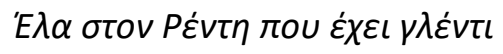

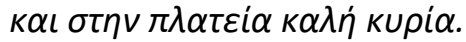

They also collaborated in assignment 8 of the think-tac-toe, created a paper microphone, put a label on it titled 'Rentis News' and interviewed each other about their neighborhoods in both countries, after having filled in a worksheet (Figure 19). In general, students' engagement in various assignments and especially in the slogan occupied them creatively and no tensions were noticed. 


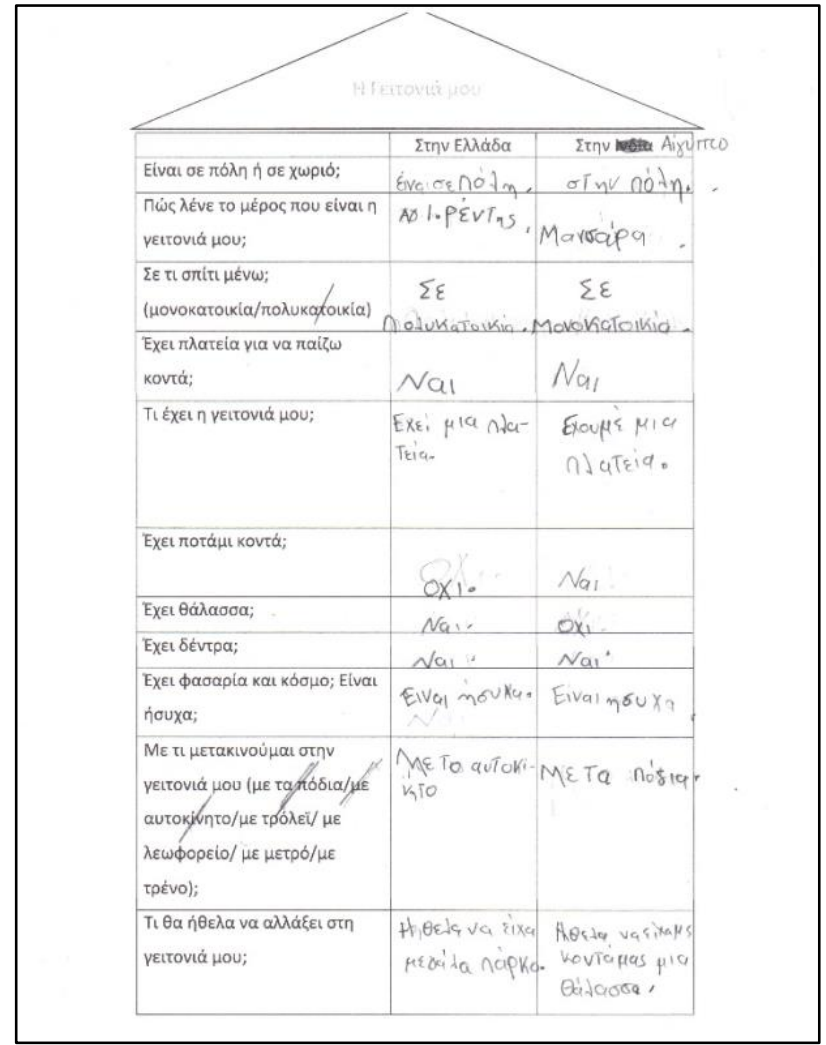

Figure 19

Neighborhood think-tac-toe (Ali)

\section{Reaction to Differentiated Instruction blended with Linguistically Appropriate Practice}

Concerning students' reaction to $\mathrm{DI}$, only one student asked the researcher why the two teams write a different number of words in the Taboo cards. Then Georgiana, showing her motivation, claimed that she will play with the difficult set of cards, although she was engaged in the easy card deck. Besides this, no other student expressed any question about the differentiated nature of the lessons.

Related to the integration of their first languages, all of them were keen on creating cards in their language and helped each other to prepare their cards. However, Ekam was less competent in writing in Punjabi claiming that he forgot writing in his language. He said that in his school in India, which was an English-Christian private school, they were punished with expulsion whenever they spoke in Punjabi. Georgiana was

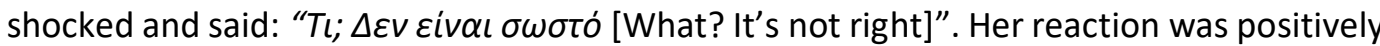
commented by the students. When they started playing in teams, they successfully codeswitched to the language of the cards (either Greek or their language). Thus, students who were fluent in English (Gurlin and Zahir) and used it more often than Greek, were exercising Greek spontaneously, without being imposed by the researcher.

In the think-tac-toe activity, students used their mother-tongue except Ekam and Georgiana. Heba added in her drawing words in Arabic (Figure 20), while Georgiana did not (Figure 21). During the slogan creation, four students out of six created a slogan in 
their mother tongue, recorded it, and felt more confident about themselves. Mohamed translated his slogan about his hometown to his classmates in a singing tone: " $\Sigma \tau \eta$

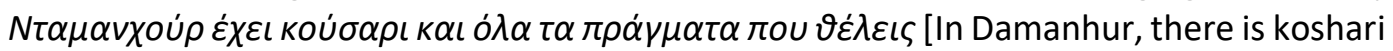
and all the things you want]". Then Ali sang his slogan in Arabic about Mansoura and explained what it says. Finally, Zahir and Gurlin recorded their slogan about Raikot (hometown) in a rap style. The researcher was surprised about students' engagement in the specific activity, as she initially thought that students would find it difficult and would not choose it.

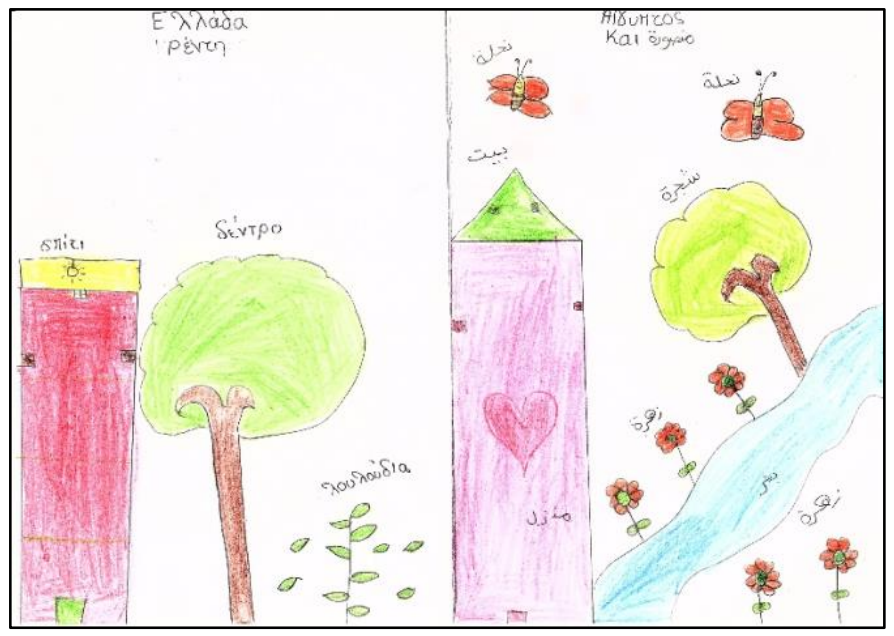

Figure 20

Neighborhood Think-tac-toe (Heba)

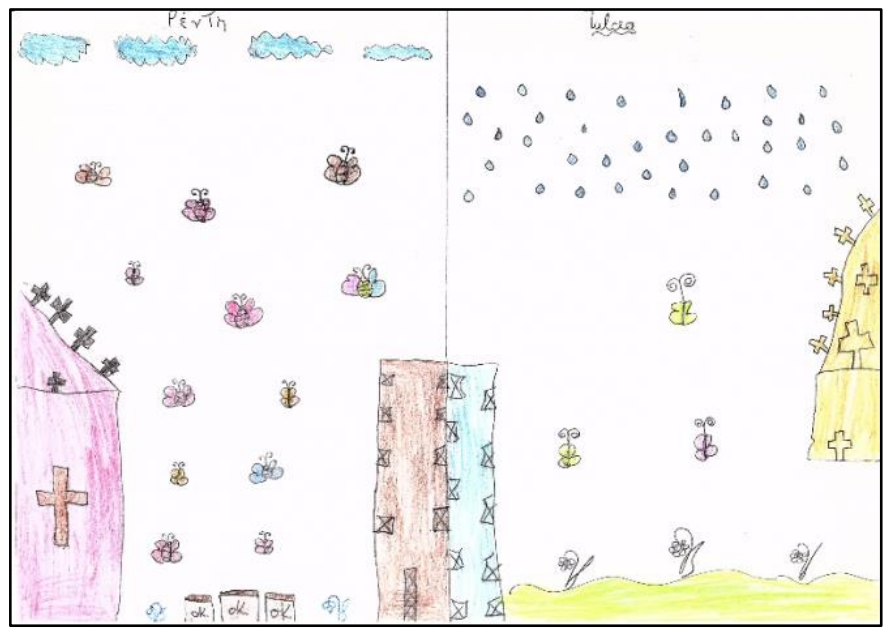

Figure 21

Neighborhood Thick-tac-toe (Georgiana) 


\section{Reflection on the outcomes of the third research cycle}

The third cycle was more successful than the other two, as students succeeded in collaborating and working in a positive classroom environment. Also, the fact that their home languages were integrated into the learning process, although initially it surprised them, later on, they used them actively. The researcher writes in her diary: "I noticed that when they were facing difficulties with the Greek Taboo cards, they were switching to the cards of their mother tongue and engaged more as they were feeling more confident. These cards helped them not to quit when they felt frustrated". Moreover, using their mother tongues was a reason for speaking more about their past, their countries and their previous experiences.

Improvement was also noticed on Georgiana's and Ekam's engagement in the learning process. The researcher reflects on it in her diary: "Before using DI, I was spending a lot of time to persuade them to sit down and participate in the lesson. During this cycle, neither of them fought with anyone and they were extremely concentrated in their assignments". However, Zahir's initial refusal to participate in the think-tac-toe activity and his desire to engage in Quizlet, as well as Ali's impetuous engagement in the comic creation preoccupied the researcher. An alternative way to apply DI combined with LAP was used in the next cycle, so as all learners engage in the learning process.

\section{Fourth research cycle}

\section{Activities implementation}

In the fourth cycle digital tools were used. The rationale behind this thought was that technology per se is a tool for differentiated learning and students seemed to be motivated by digital tools. As experienced in the previous cycles, learners often felt demotivated and frustrated due to language difficulties. Thus, technology-mediated instruction aimed to benefit students by stimulating them although the researcher was reluctant about using digital tools, as learners were not acquainted with them. Thus, Activity 7 entailed an avatar creation through Voki application, while Activity 8, introduced students to My Maps application, where they would connect their towns of origin with their town of current residence.

During the first two hours of this cycle, learners were encouraged to explore the Voki interface and create an avatar. Two computers were available thus, two teams were formed. Ekam, Mohamed, Georgiana and Heba were in the first team and Zahir, Gurlin and Ali in the second. In the beginning, the researcher demonstrated to the whole classroom her avatar in order to stimulate them to engage in the activity. All students created their speaking avatar and set as a background a photograph of their hometowns within two hours. Respecting students' different learning styles, three of them recorded the avatar's message, while the rest typed it. Examples of some avatars are shown in Figure 22.

In Activity 8, My Maps application was introduced to students. Two layers were created by the researcher named Our towns and The journey. The researcher showed how to add a pin to a place on the map and pinned her hometown. Consequently, in the same teams and in sequence students pinned their hometowns. Heba pinned Agios loannis Rentis. Then, students uploaded a photograph of their hometown and typed a description of it. Afterwards, students were urged to draw lines showing their journey to Agios loannis 
Rentis and label them, such as 'To $\tau \alpha \xi i \delta \iota$ tou Ekam' [Ekam's journey]. Each line was colored differently and by clicking on it, students' avatars, created in the previous lesson, were added by the researcher as it demanded more ICT skills, that students lacked. The outcome at the end of the lesson is presented in Figure 23.

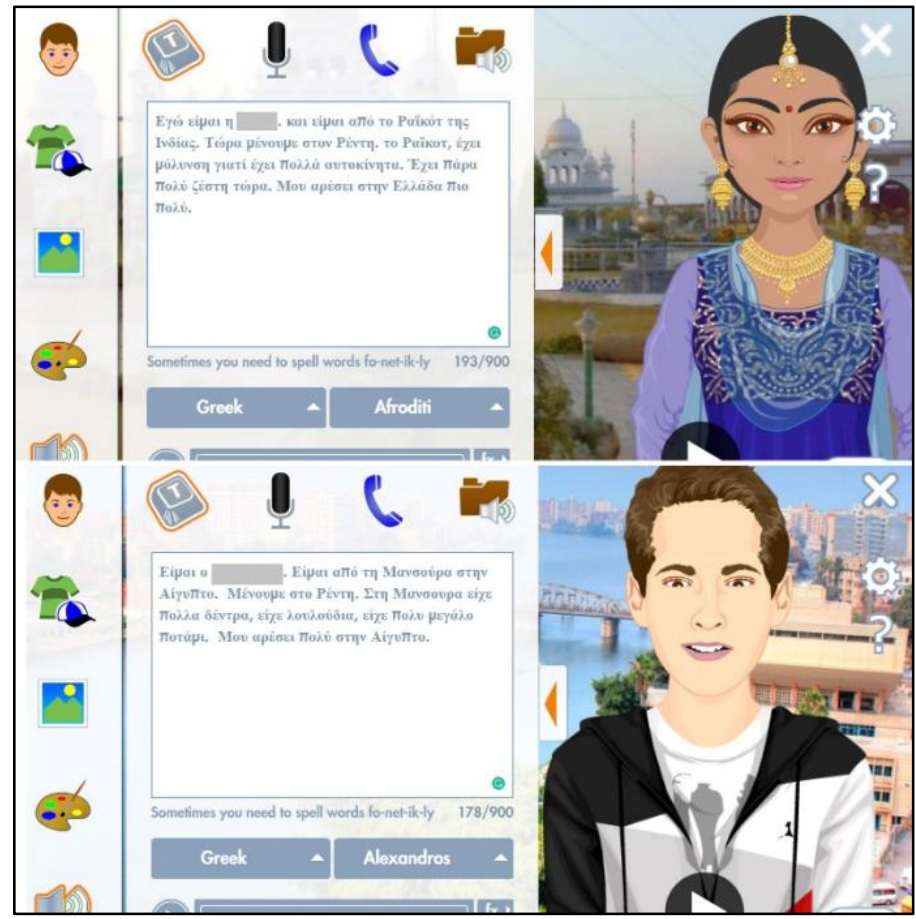

Figure 22

Avatars' creation

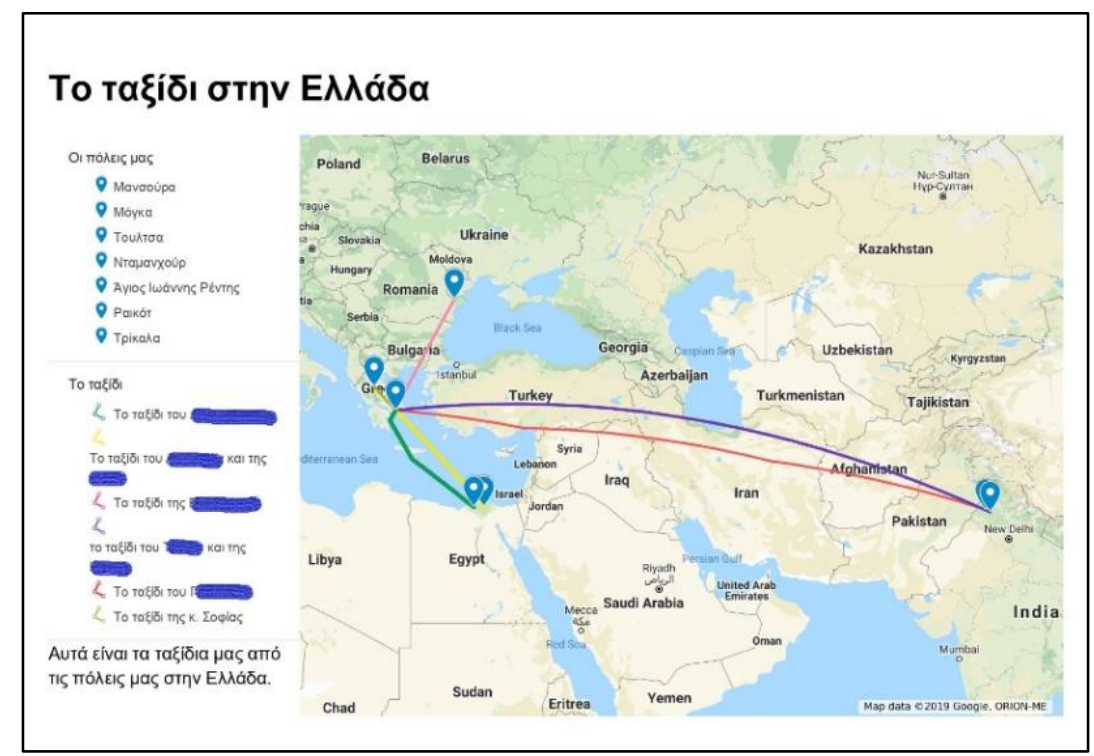

Figure 23

My Maps interface 


\section{Students' motivation}

Students were keen on creating avatars in activity 7. In order to help students, the researcher urged whoever student needed it, to answer questions about themselves in their notebooks before typing or recording their avatar's message. Some samples of their answers are shown in Figure 24. Mohamed and Gurlin did not write in their notebooks, as Gurlin preferred to type directly in the computer and Mohamed recorded his avatar message.

Heba showed her motivation when she requested to remain in the classroom during the break, in order to finish her avatar. Moreover, Gurlin, Ekam and Ali requested the webpage address in order to create an avatar at home and gave their pencil to the researcher in order to note the address in their notebook. Only one student, Zahir, initially expressed his denial to participate. The researcher was surprised by his negativity, as he enjoys technology. He explained that he did not know how to make it. However, his denial was temporary and the researcher interpreted it as a sign of low confidence on his behalf, which he overcame with scaffolding.

Additionally, all students were motivated by the My Maps activity, as they traced their country in the map, uploaded a photograph of their city, compared their journeys from their country to Greece and watched all avatars pinned in each city, speaking about their hometowns. When students traced their cities on the map, they expressed their

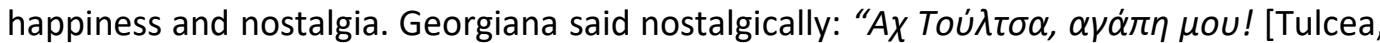
my love!]". Ali and Heba yelled: "Al Mansura!". When Ekam viewed his town requested from the researcher to photocopy it in order to take it with him at home. However, their motivation was also apparent when they traced their neighborhood in Agios loannis

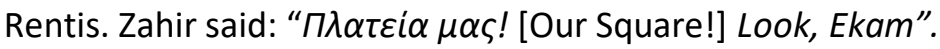

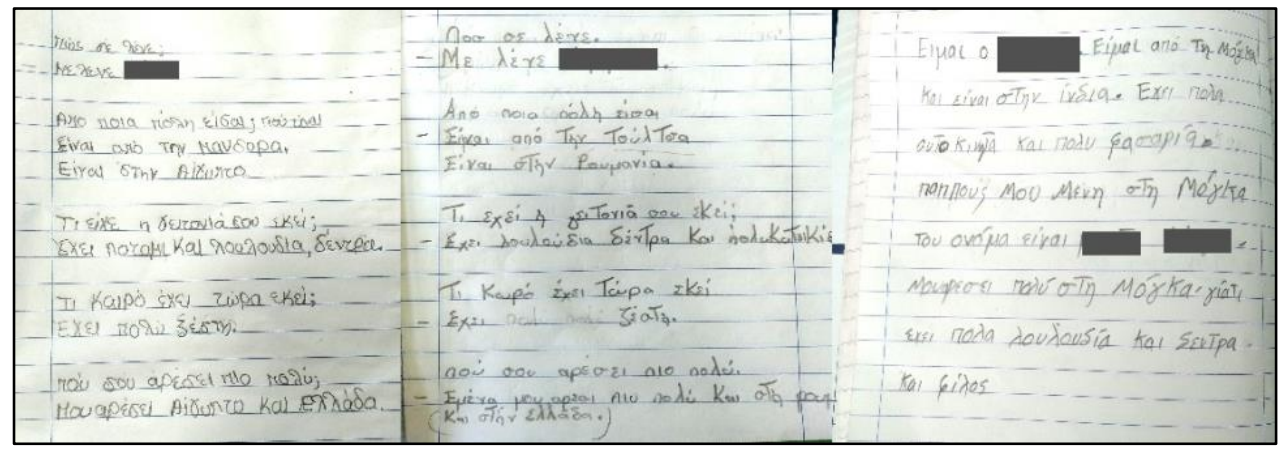

Figure 24

Samples of students' notebooks during the avatar creation

\section{Students' relationship}

Through both activities, students were encouraged to talk about their past, their relatives residing in their countries and their neighborhood in their hometowns. This ameliorated their relationship, as they had the chance to get to know each other better. For instance, Georgiana left for a while the classroom and missed Ekam's town tracing on

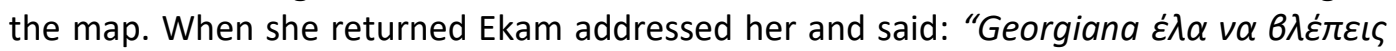


Мо́үка. [Georgiana, come to see Moga]". Georgiana also praised Ekam's avatar by saying

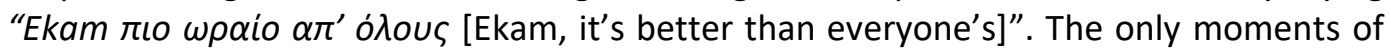
tension were noticed when students were disputing about the time each one was using the computer, during the avatar creation. These disputes were expected by the researcher, due to the limited available infrastructure. However, they were soon overcome.

\section{Reaction to Differentiated Instruction blended with Linguistically Appropriate Practice}

During the fourth cycle, students did not comment on the lesson's differentiated nature as they were starting to be acquainted with DI. As far as it concerns LAP, students compared their country's acreage and its distance from Greece. Mohamed was observant and noticed that when clicking on each journey line, its length in kilometers appeared. This was an opportunity to classify countries depending on their distance from Greece. Thus, although initially, students were claiming that their country was bigger than others and the most far away, after Activity 8, they all became aware of their country's position on the globe and its acreage. Moreover, integrating students' cities in the lesson, triggered conversations about their lives and past experiences. During the avatar creation, Heba expressed her admiration on the 'different', such as the Indian clothes and jewelries.

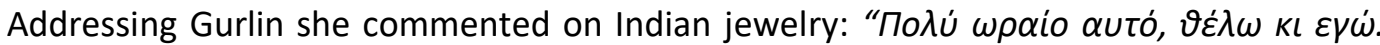

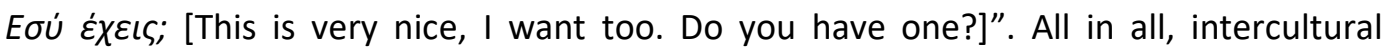
awareness was promoted, which was one of the researcher's goals.

\section{Reflection on the outcomes of the fourth research cycle}

Fourth cycle's objectives were satisfied. Although the researcher was reluctant about the integration of digital tools in the learning process, as ICT skills were demanded, all students participated actively, except Zahir who was temporarily negative before engaging in the activities. Moreover, their relationship improved perceptively, and the researcher attributed this to the intercultural awareness promoted by both activities. The cycle's disadvantage was that due to limited infrastructure, there were disputes about the time available on the computers and thus they were more energetic than usual.

Reaching the end of the research cycles, the researcher noticed that during the four cycles differentiation was mostly related to the product. This was taken into account for the design of the last research cycle, where differentiation of content was applied, through three learning centers.

\section{Fifth research cycle}

\section{Activities implementation}

In this cycle, three learning centers were created, related to traditional clothes from students' countries. The relevant vocabulary was introduced through Quizlet application before the fifth cycle. Students were urged to engage in the teaching materials by forming teams taking into account their preferences and their pacing. Also, their first languages were integrated into the materials. Moreover, since My Maps activity was successfully integrated into the previous cycle, the application was used as a presentation tool of students' work. 
The researcher tried to adjust the classroom accordingly (Figure 25), however, its size did not permit big changes. In Table 10 students' engagement in the three learning centers is presented.

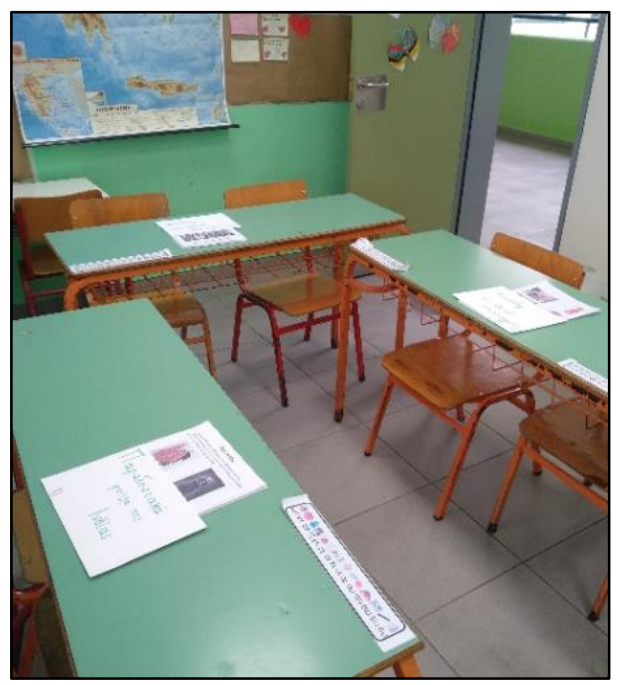

Figure 25

The three learning centers

\begin{tabular}{|l|l|l|}
\hline Learning center & Learning center name & Students engaged \\
\hline 1 & Egyptian traditional clothes & Ali, Heba, Mohamed \\
\hline 2 & Indian traditional clothes & Gurlin, Zahir, Ekam \\
\hline 3 & Romanian traditional clothes & Georgiana \\
\hline
\end{tabular}

Table 10

Students' engagement in each learning center

Through the materials, students were expected to develop intercultural awareness by naming their country's traditional clothes and accessories (Figure 26), relating their country's weather with clothes (Figure 27), answering questions about these clothes or accessories (Figure 28) and drawing their country's most famous traditional clothes (Figure 29). Students' first languages were also welcome throughout all materials. Since Georgiana was the only Romanian student, she worked individually, although the researcher urged Heba to collaborate with her. The researcher clarified that students had four hours in total to complete all activities in any sequence and present their work to the whole class. All students managed to complete and present all activities. 


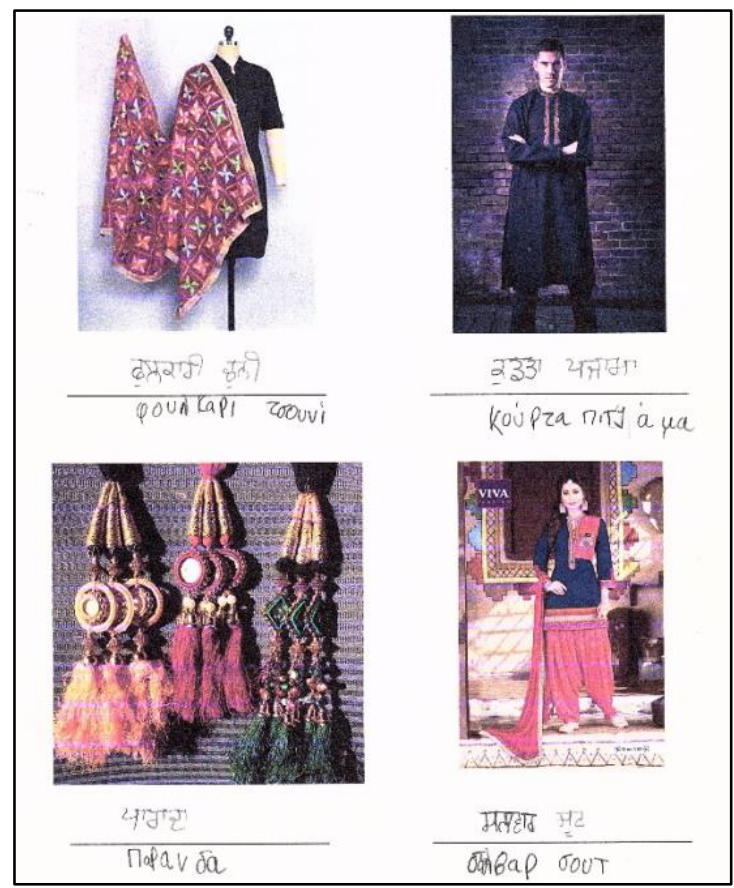

Figure 26

Activity 1 - Learning center 2

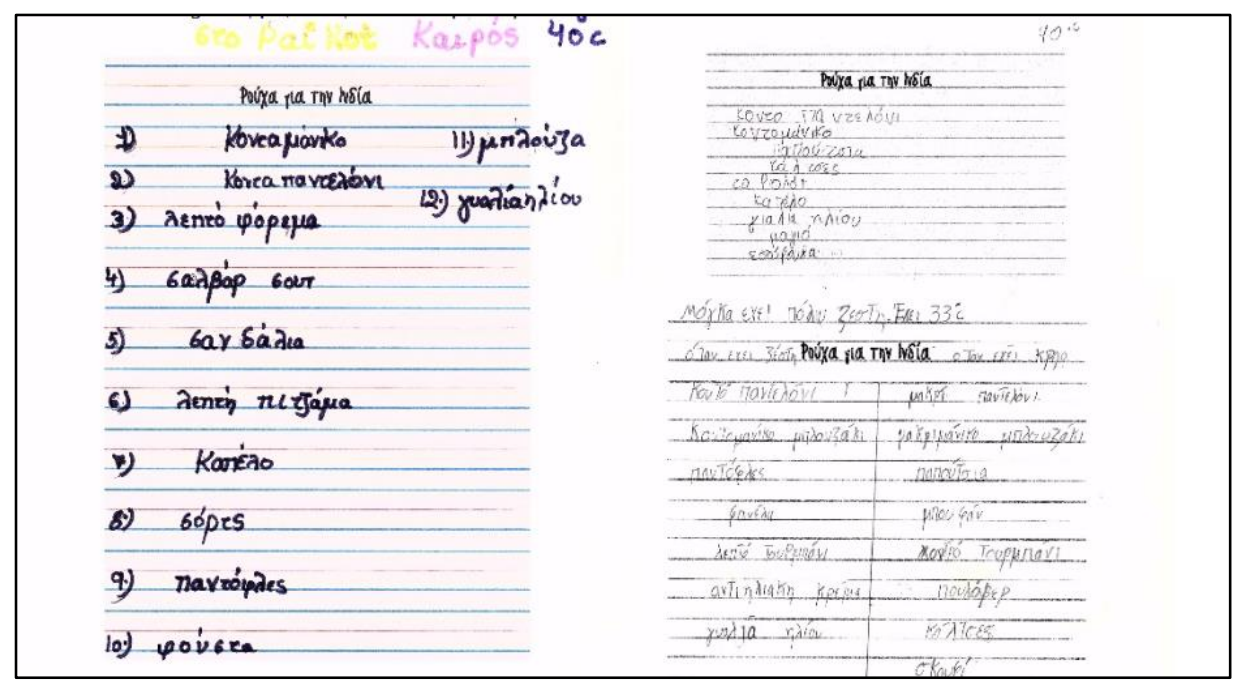

Figure 27

Activity 2 - Learning center 2 


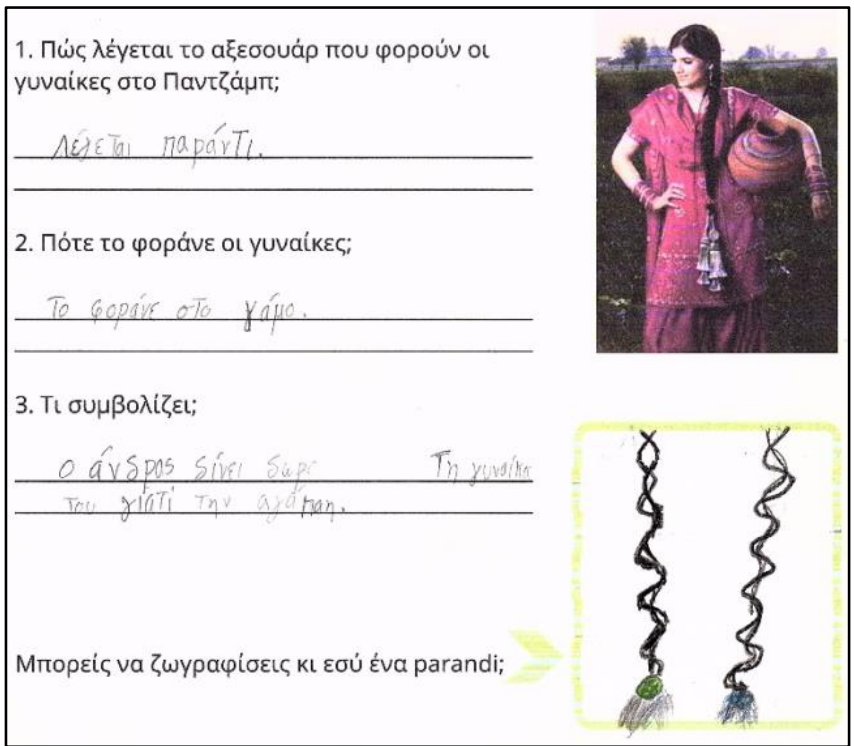

Figure 28

Activity 3 - Learning Center 2

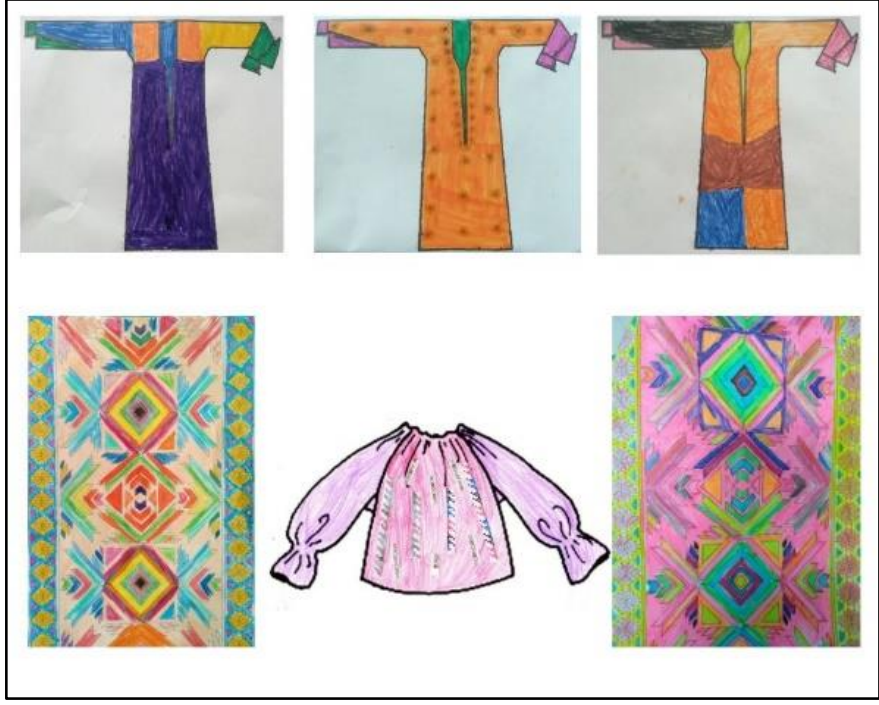

Figure 29

Traditional clothes drew by students

\section{Students' motivation}

During the four hours of this cycle, students were motivated to complete the activities of the materials. Being free to choose the sequence of the activities helped them to begin with the activities they enjoyed most. Additionally, the fact that the materials entailed their country's cultural elements, stimulated them more to complete the activities, talking about their past experiences in their countries:

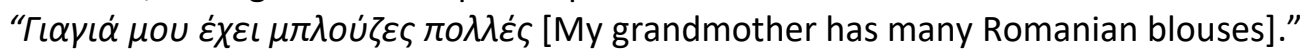




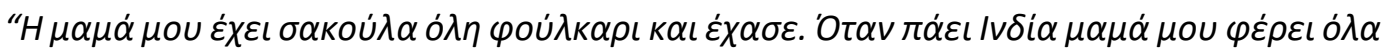
$\varepsilon \delta \dot{\omega}$ [My mother had a bag full of Phulkari and lost it. When she goes to India, my mother will bring them here]".

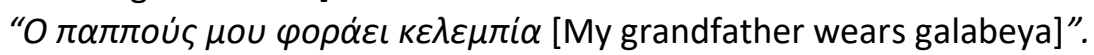

Furthermore, supplementary material was added by Zahir who searched a song talking about the Indian scarf, phulkari on the internet. All Indian students knew the song. The researcher urged them to upload the video on My Maps. Zahir said: "Good idea". This showed his motivation.

\section{Students' relationship}

The Indian students collaborated successfully during this cycle. On the other hand, Heba collaborated only in the first activity with her team and the rest activities were completed individually stating that she prefers to work alone. Furthermore, although they were more energetic, there was no tension between them. On the contrary, when the Indian students presented the phulkari song, the other students commented on how

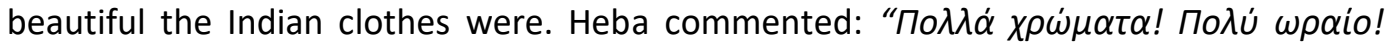

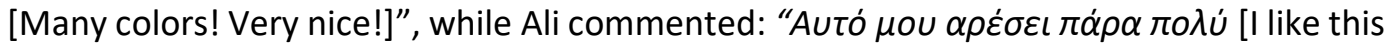
very much]". Intercultural awareness which was promoted improved students' relations.

\section{Reaction to Differentiated Instruction blended with Linguistically Appropriate Practice}

In the last cycle, students did not comment on the differentiated nature of the lesson, apart from Georgiana who complained that drawing a motif for the Romanian blouse was more difficult than the other students' drawing assignments. The researcher urged her to continue with the easier motif, as indeed, the one motif was more difficult.

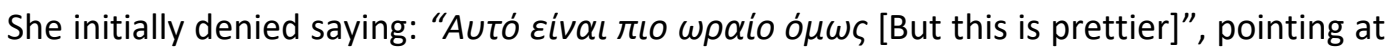
the difficult motif. However, later on, she engaged in the easiest but felt frustrated for quitting the first motif. Her bad mood was illustrated in the next activity she engaged, in which she answered the questions in one word (Figure 30). This made the researcher think that when students choose between an easy and a difficult assignment, they both should be motivating for them.

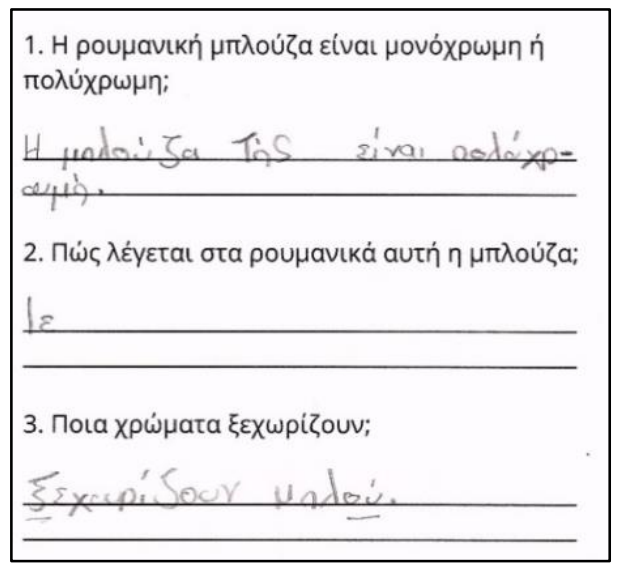

Figure 30

Activity 4 - Learning center 3 
Concerning the use of the first languages in this cycle, this occurred more natural, as students were experienced from the previous cycle (Figures 31-35). Finally, the use of intercultural elements in the learning process started having an effect on students' and teacher's relationship. Ekam said that his mother will give a salwar suit as a gift to the

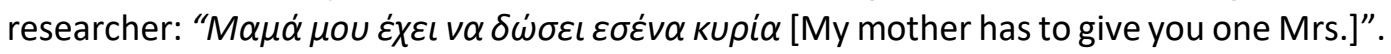

\begin{tabular}{|c|}
\hline 1. Kapraill \\
\hline 2. zoup irós \\
\hline 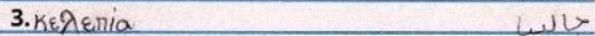 \\
\hline 4. $\gamma_{n} \lambda_{1}^{\prime} k$ \\
\hline 5. Jaida \\
\hline 6. $5 a \dot{\lambda}$ \\
\hline 7. rapxá - paviriza \\
\hline 8. Kenerria \\
\hline
\end{tabular}

Figure 31

Activity 1 - Learning center 1

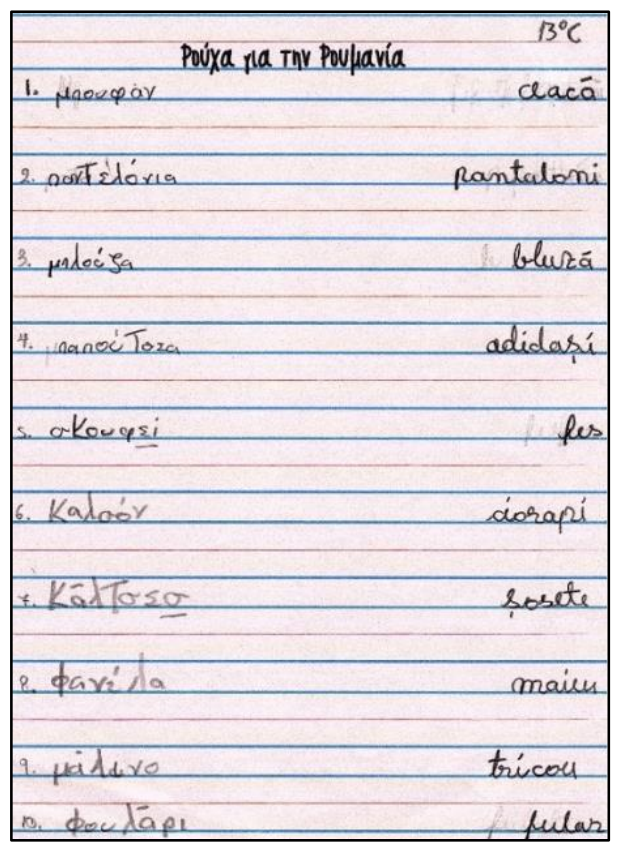

Figure 32

Activity 3 - Learning center 3 


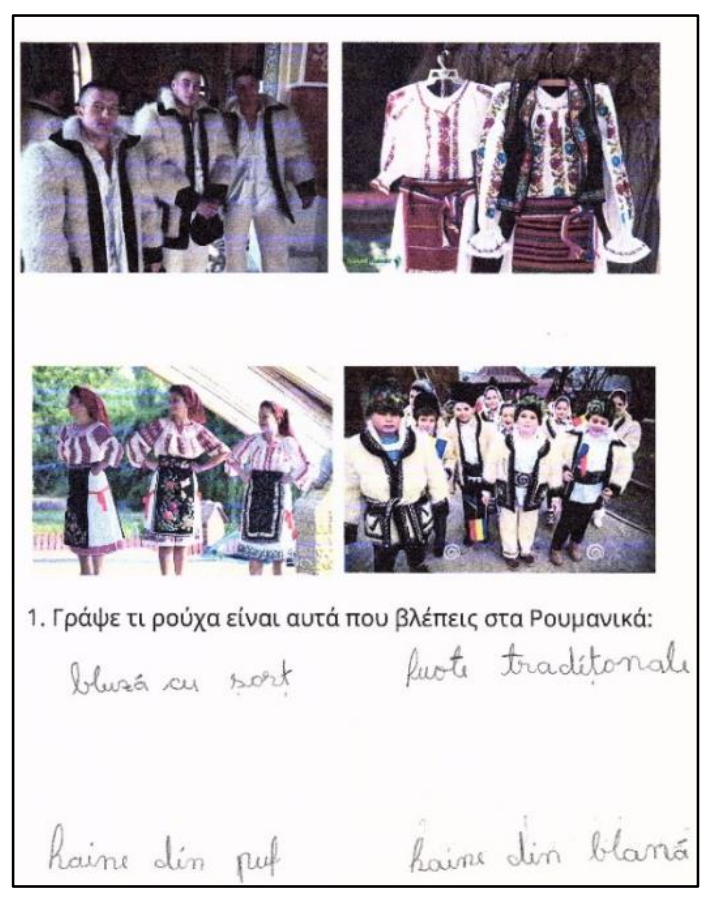

Figure 33

Activity 1 - Learning center 3

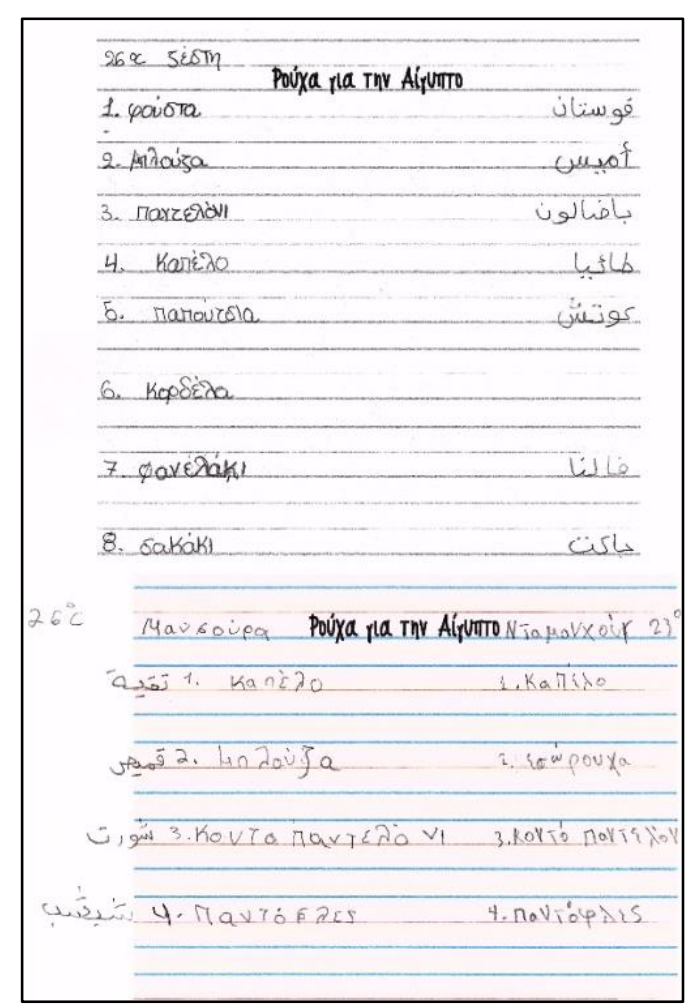

Figure 34

Activity 2 - Learning center 1 


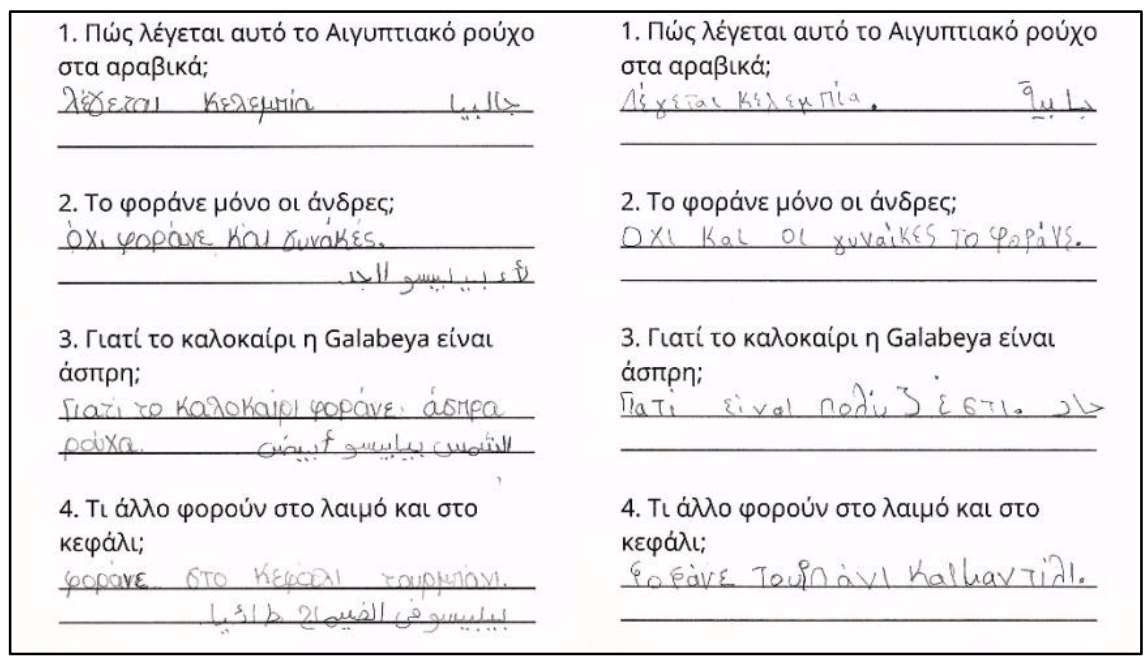

Figure 35

Activity 3 - Learning center 1

\section{Reflection on the outcomes of the fifth research cycle}

With the completion of the fifth research cycle, teaching interventions were completed. In this cycle, differentiation of content was applied. Through students' engagement in the learning centers and by being encouraged to respect one's personal learning pacing and preferences, students were more autonomous and this was reflected on the researcher's limited interference. Moreover, students used their first languages effortlessly, apart from those who were not competent in writing (e.g. Ekam). Also, using the digital map from the previous cycle for presenting their drawings and the song's video, operated as a digital bulletin board, where students could continue uploading their work, so that members of their family could see.

However, although collaboration was promoted by the researcher, only three students collaborated effectively, while in the Egyptian team, Heba preferred to work individually. Initially this preoccupied the researcher, but later she realized that Heba's denial to collaborate was due to her different learning style, not to her disability to collaborate, given that her relationship with the team was good. Thus, this cycle helped the researcher to detect students' differences in learning styles which were not so obvious to her.

\section{Focus group findings}

After the five research cycles completion, the researcher in order to explore students' perceptions on the implementation of DI blended with LAP, conducted a focus group discussion with all students. The themes that emerged after the data analysis are presented below and students' quotes are translated:

\section{Varying materials and assignments}

In the researcher's question about students' perceptions on choosing among various activities, they all agreed that they liked it. Some students' answers were: 
"Oh yes. I liked this very very much".

"I liked it because it was like a game".

"Mrs., I want to choose difficult...Because I want to be good in Greek".

In the question about choosing between instruction from the book or $\mathrm{DI}$, students' responses varied. Heba responded that she preferred DI, while the others were not clearly in favor of one approach over the other, with Ekam responding that he didn't like the book as it had difficult exercises. However, Georgiana was the only student favoring the book, explaining that it had many exercises and through the book, she was learning Greek grammar, whereas during the research cycles she did not engage in exercises. She pointed at her advertisement about the Romanian sweet Cozonak and said: "Yes Mrs. these are Cozonak" meaning that it was not an exercise. Concerning their opinion on the activities, the most preferred ones are presented in Table 11.

\begin{tabular}{|l|l|}
\hline Activity & $\begin{array}{l}\text { Number of students who enjoyed the } \\
\text { activity }\end{array}$ \\
\hline Taboo game & 7 \\
\hline Avatar creation & 3 \\
\hline Slogan creation & 3 \\
\hline Assignments through RAFT strategy & 3 \\
\hline My maps application & 2 \\
\hline Drawing of students' Neighborhoods & 2 \\
\hline Learning centers & 2 \\
\hline Comic creation (Think-tac-toe) & 1 \\
\hline Transnational menu & 1 \\
\hline
\end{tabular}

Table 11

Students' preferred activities

\section{Use of students' mother tongues}

In the question about the use of students' languages during the learning process, all students positively commented it, apart from Zahir who was not feeling confident about writing in Punjabi and said that he does not need to enhance his writing skills as he will use English if he returns to India. However, practicing his oral skills in Punjabi was positively commented by him: "I liked it because I spoke in Greek and Punjabi." Other students' answers are presented below:

"I enjoyed when I wrote in Punjabi and when I wrote in Greek how to write in Punjabi". "If we go to other countries, we know the languages. And it's nice to learn, to know. If you go somewhere and you don't know the language, it's better to learn it."

"I say to my mother, I want to learn to write in Punjabi...My mother said if you go to India and someone tells you to write in Punjabi and you say no, they will laugh at you."

\section{Language awareness}

In the researcher's question about their languages' difficulties, the majority of students responded that the Arabic language is the most difficult, while Georgiana said that Punjabi is the most difficult and demonstrated a greeting sign in Punjabi and said "Look at the letters. Very difficult". 
Concerning their desire to learn one of their classmates' language, all students chose a language and they tended to select according to the affiliations developed with their classmates. For instance, Heba and Georgiana responded that they desired to learn each other's language, as they are friends. Furthermore, Ekam responded that he would like to learn all his classmates' languages.

\section{Intercultural awareness}

In reference to the intercultural awareness promoted by the activities all students commented that they liked their counties' integration into the thematic units. Some relevant answers justifying their satisfaction are presented:

"I liked it, we all together team".

"Because it's our countries... We remembered our country. That we want to go to that country".

"I liked it, we learned about Egypt, Romania. Then, I will go when I grow up with my friend Egypt. I will go to Ali's and Mohamed's house to learn how they are".

"Yes, because all countries are together and we see things about our countries. Not just our country, and Greece, India and Romania. I liked that we did recipes from our country and all the countries".

\section{Practices used in the mainstream classes}

Concerning the practices used in their mainstream classes regarding activity choice, students responded that they don't regularly choose, except Ekam who responded that he and Zahir write easier tests in Greek than the other students. In reference to presenting their work in the whole class they responded that they don't present their assignments, apart from writing exercises on the board, while Georgiana said that she presents her drawings during Art Lessons.

In relation to intercultural education promoted in their mainstream classes, students mentioned that they don't usually talk about their countries. Although the majority wanted to talk more about their countries in the mainstream class, Georgiana answered negatively, as she gets emotional when remembering her country. She characteristically said:

"I don't want to talk... Because I want to cry...Because I want to be where my father is, my grandmother, my grandfather, my cousin...Yes, later, if I go to Romania I will cry because I'm not here".

Finally, in the researcher's question whether they would prefer the lesson in the mainstream class to be conducted as in the RC they all responded positively. More precisely, some answers were:

"It's very nice, it's fantastic".

"I liked it. It's easy".

"Because we were playing".

"We play and learn".

\section{Discussion}

The study explored the impact of this blending on students' engagement in the learning process which was the main problem triggering this research. Students were not 
proceeding academically as they were showing limited engagement in the educational process. Through the implementation of the five cycles, findings showed that the new practice increased their engagement in the learning process. With the completion of all research cycles, students' voices were heard enabling CLD students to become actors rather than mere research subjects.

\section{The impact on students' engagement}

Throughout all the research cycles, students' engagement increased. This was attributed to the combination of three elements: a) they showed increased motivation, b) their relationships improved which ensured a peaceful learning environment and c) they accepted the new practice without having serious reservations. This outcome was achieved gradually over the five research cycles. Besides, DI as an approach to teaching relies on constant evaluation and reflection of the strategies used, due to its dynamic nature (Valiandes \& Koutselini, 2008).

\section{Students' increased motivation}

Most of the activities implemented were based on students' preferences and interests. Corresponding to the studies conducted about interest-based instruction (Collins \& Amabile, 1999; Sharan \& Sharan, 1992), almost all students showed intrinsic motivation and commitment to the activities with the necessary scaffolding. This contradicts the students' usual indifference to the exercises and whole-class activities which were inefficiently used in the past. The blended approaches seemed to have a positive impact especially on students who were mostly unresponsive to the whole-class instruction. For those students, there were moments of complete commitment to their work similar to what Csikszentmihalyi (2014) described as the flow. Thus, a basic component of $\mathrm{DI}$, the opportunity to choose among various assignments, operated several times as a springboard to productive engagement.

Also, increased motivation stemmed from the nature of DI which tries to include all students' personal traits, interests, learning profiles and their various levels of readiness (Koutselini, 2008; Tomlinson, 2001; Valiandes \& Koutselini, 2008, 2009). Trying to correspond to students' variance was beneficial for their engagement in the learning process, as their self-confidence was enhanced, a necessary element, as Sfyroera (2004) states, in order to dare to engage in activities which they initially thought that they could not manage. On the contrary, when students' variance is not taken into consideration, struggling students will remain excluded, feeling unsuccessful.

Increased motivation was also noticed, as most of the activities were meaningful to them, making use of a plethora of materials, offering multiple modes of expression, while some of them entailed playful and experiential characteristics, making learning more pleasant. DI should respond to students' affective needs during the learning process (Tomlinson \& Imbeau, 2010). Thus, ensuring a pleasant, playful and positive classroom environment is a step towards catering to the affective needs of all learners in the classroom.

In addition, the linguistic and cultural acknowledgement that LAP activities espouse, led to the affirmation and empowerment of students' identities, maximizing their motivation about the learning process, as the content of instruction was relevant to their lives and experiences. An inclusive practice such as LAP invested in students' 'funds 
of knowledge' which contributes to academic learning (Delpit, 2002; Gee, 2004; Manyak, 2006). The use of students' home languages offered them a sense of success and selfachievement when they were feeling deficient in the second language, avoiding feelings of frustration which were often experienced in the past. It is worth noting that students became accustomed to using their first languages in the RC gradually, albeit being prompted to use them during the first two cycles also. With the passage of time, home languages were integrated into the instructional practice more easily and effortlessly. This remark is associated with students' unfamiliarity of how to use their home languages during instruction, a practice that was missing from their mainstream classes.

However, there were still students who occasionally felt frustrated during their engagement in the activities. This was interpreted by the researcher as a result of two elements: there was either a misjudgment of students' level of readiness or students made bad choices as they tended to get influenced by their classmates. The former triggers the need to mention the critical role of the researcher-educator, who is obliged to carefully assess students' level of readiness in order to correspond to their ZPD. Too difficult tasks, without the proper scaffolding techniques, might frustrate struggling students and demotivate them (Bransford, Brown, \& Cocking, 2000). As scholars state in order to satisfy the varying needs of all learners, educators should "have an accurate view of students' levels of understanding, and that they know which instruction and learning activity is appropriate for children at different levels, given the goal they strive for" (Deunk, Doolaard, Smale-Jacobse, \& Bosker, 2015, p. 52). The latter shows students' weakness to make suitable choices concerning the activities they prefer, as most of them, were accustomed to teacher-centered instruction, with a 'one-size-fits-all' orientation, leaving no space for personal preferences and expression. Thus, when incorporating new, unfamiliar instructional practices, a time of adjustment on these practices is needed.

\section{Students' improved relationships}

As described, a major problem impacting students' engagement in the learning process, was their tense interpersonal relationships. This problematic behavior which in the past was a cause for academic stagnation, improved remarkably, throughout the five research cycles, affecting positively their engagement in the activities. Although during the first cycle, there was a slight improvement, with the passage of time, students were able to collaborate with each other and to accept 'otherness' by praising each other's work or other cultural characteristics.

The improvement of students' relationships was mainly attributed to the integration of LAP within the DI framework. This improvement was more evident on the students whose relationship was tenser. Throughout the thematic units and gradually, cultural and linguistic awareness were promoted. Amelioration was attributed to the integration of multicultural and plurilingual elements into the content of instruction, as students had the opportunity to know each other better. As Cummins (2017) mentions, usually CLD students are treated with 'benign neglect', meaning that their linguistic and cultural diversity is positively seen, but not practically invested in the learning process. In the context of the present study, students' linguistic and cultural capital was used as a resource in teaching, resulting in the establishment of a rapport with their classmates and the researcher-educator. 
Consequently, educating students to embrace diversity is of major importance, taking into account the broader sociopolitical context within which they live. ChumakHorbatch (2012) describes LAP as a practice which opens the door to all languages by giving them a place in the classroom. At the same time, all students experience linguistic and cultural diversity, which helps them to realize that diversity is everywhere in society, corresponding to the CRT indicator that Ladson-Billings (2001) proposed. After all, the aim of multicultural education is to promote apart from human development, education equality and academic excellence, the value of democratic citizenship (Banks \& Banks, 2001; Nieto, 2012). Thus, students needed to develop skills in order to relate with each other in a positive way, regardless of their differences. With culturally and linguistically responsive teaching, behavioral challenges and interpersonal tensions are decreased (Hollie, 2012), a fact that was noticed in practice, in the context of this study.

Moreover, the fact that students received meaningfully differentiated instruction through interest-based activities occupied them creatively, hence their will to engage was stronger than their hesitation to collaborate. Furthermore, through flexible grouping, students had the opportunity to develop collaborative skills in various contexts, with classmates that initially seemed a mismatch, resulting in a peaceful and positive classroom environment, enhancing thus, their engagement in the learning process. As argued in literature, "basic pedagogical skills such as classroom management skills and ensuring a safe climate can be regarded as prerequisites for differentiation" (Geel et al., 2018, p. 63).

\section{Reactions to the new practice}

Given that students were used to a more teacher-centered and whole-class instruction, where adaptation of materials and practices were not the norm, the researcher was reluctant about students' reactions towards the new practice. Her hesitations mostly concerned the way students would react towards the differentiated nature of the lesson, namely, whether they would accept it smoothly without serious reservations.

Indeed, students initially were wondering about the nature of the differentiated lesson. However, this was noticed only in the beginning of the research, when students were not acquainted with the new practice. Tomlinson and Imbeau (2010) emphasize the importance of dedicating teaching time in order to prepare students for differentiation with start-up and follow-up conversations. Although educators tend to avoid this step, studies showed that when teachers share their vision about their work, their practices are better applied and eventually time is gained rather than lost (Marzano, Marzano, \& Pickering, 2003; Stronge, 2002). In order to avoid students' negation to engage in different assignments, some DI strategies which were used supported subtle differentiation (such as the think-tac-toe), something that facilitated differentiation without being noticed by the students.

\section{Students' perceptions on the use of the new practice}

As mentioned, the research follows the philosophical assumptions of the transformative worldview. Thus, the participants' perceptions of the new practice were one of the researcher's objectives, given that CLD students are often marginalized, seen as speechless in their mainstream classes (Krumm, 2007). Their experience on the new 
practice thus, is valuable as it provides insight into the way the recipients of instruction perceived the blending of the two practices while the practitioner profited from the knowledge gained through students' answers which facilitates the formation of an action agenda.

More precisely, all students were pleased about the varying materials and assignments used during the research cycles. Having limited or no experiences on DI in their mainstream classrooms, they positively commented on the opportunity to choose what interested them most. Moreover, due to the DI techniques, many activities were playful and students seemed to estimate this characteristic (the taboo activity was the most preferred one). However, it is worth noting that students, especially those who are accustomed to more traditional instructional practices, might underestimate instruction which is divergent from the one they are used to. This was recorded in Georgiana's answer, who did not realize that she was still practicing the Greek language without following a focus on forms approach (Long, 2015), namely without engaging in exercises and grammatical drills. As Dryden-Peterson (2015) mentions, past experiences on teacher-centered pedagogies impede students' adaptation to more student-centered pedagogies.

Another issue that emerged from students' answers was that of the educator's misjudgment about students' choices regarding the activities. It was noticed that despite the researcher's low expectations regarding certain activities (slogan creation, use of ICT), due to their degree of complexity, students classified these activities in high order when they were asked to express their preferences. This affirms that even educators are prejudiced concerning migrants' linguistic competence. Thus, careful assessment of learners' competence and keeping in mind to offer challenging activities which promote academic growth are essential before jumping into false conclusions. Educators should remember that instruction should always be in advance of students' current level of mastery in order to promote development (Tomlinson et al., 2003). This results in engaging in challenging activities, especially when they feel that error making is allowed and not punished (Sfyroera, 2004).

Concerning their opinions on the multilingual aspect of the instruction, all students seemed to favor the fact that their languages were used in the classroom. The major benefit of the integration of students' mother tongues in the learning process, was that they realized their value. A student who was starting to lose his first language, after the completion of the research was convinced that he should start lessons in his mother tongue during the summer. As Wong Fillmore $(2000$, p. 207) claims immigrant students often face a tremendous problem: they struggle to maintain "their sense of worth, their cultural identities and their family connections as they become assimilated into the school and society".

Students were also positive about intercultural awareness they experienced throughout the research. It was noticed that this awareness facilitated the building of strong connections between them and the teacher as well. These connections had an impact on students' motivation to participate in the lessons. Since the researcher was also students' educator, during and after the completion of the research, it was noticed that students wanted to participate in supplementary lessons in the RC even though it was not on their schedule. This showed their need to express themselves, to talk about their past experiences and to connect with their classmates and the educator. Hence, it was 
confirmed that in order to proceed academically, an interpersonal pedagogical space between teacher-student interactions is essential (Cummins, 2001b). As students responded, in their mainstream classes there were limited opportunities to talk about their cultural background, something that they would desire. However, any reference to their past should be made with sensitivity, as potential traumatic experiences may come to the foreground. Acculturation process which occurs in migrant students, "can be a mourning process, because it can imply a loss of what is familiar, such as language, home, relationships, places, and weather" (Wiese, 2010, p. 144). This was reflected in Georgiana's answer who responded that she does not want to talk about her country because she gets sad and nostalgic. It seems that migrant students' identities endure changes that may be painful and even lead to mental health problems or identity crisis (Bhugra, 2004). Hence, CLD students should be treated with extra sensitivity in order to ensure a painless integration into the host country.

\section{Conclusion}

Research findings showed that the blending of the two inclusive practices had a positive impact on CLD students, as they enhanced their engagement in the learning process, facilitating learning. Students expressed their positive experiences towards the new practice as they developed language and intercultural awareness while engaging in creative activities corresponding to their level of readiness, their interests and their learning profiles. As presented, although DI and LAP have commonalities, as they aim at addressing all learners' differing academic, linguistic and cultural needs, they were both investigated separately. Mere implementation of DI techniques set in irrelevant content, with no reference to students' diversity in terms of culture and language is a colorblind pedagogy (Santamaría, 2009). On the other hand, blending DI with LAP contributed to the investigation of interculturally differentiated teaching (Valiandes et al., 2018). Consequently, differentiated lessons were enriched with LAP activities, which use as a resource, learners' cultural and linguistic capital.

This study may facilitate professionals and institutions who desire to alter the monolingual practices which see students as copies of the same image (Koutselini, 2006), or the factory approach to instruction which is usually implemented in schools (Tomlinson et al., 2003). Research-based instruction, not only benefits learners but practitioners as well, contributing to their professional development towards a democratic educational setting. As Tomlinson and Imbeau (2010) state, educators who desire to be responsive to their pupils, need to be proactive, meaning that they should be cognizant of patterns which provoke problematic behaviors. By ensuring that students work in a safe classroom environment, where they feel appreciated and by engaging in challenging and personally or culturally relevant activities, teachers eliminate problematic elements which have a negative impact on learning.

\section{References}

Altrichter, H., Feldman, A., Posch, P., \& Somekh, B. (2007). Teachers investigate their work. London: Routledge.

Baker, C. (2006). Foundations of bilingual education and bilingualism. Clevedon, UK: Multilingual Matters. 
Banks, J. A., \& Banks, C. A. M. (2001). Multicultural education: Issues and perspectives (4th ed.). Boston: Allyn and Bacon.

Banks, J. A., Cookson, P., Gay, G., Hawley, W. D., Irvine, J. J., Nieto, S., ...Stephan, W. G. (2001). Diversity within unity: Essential principles for teaching and learning in a multicultural. Phi Delta Kappan, 83, 196-203.

Bhugra, D. (2004). Migration, distress and cultural identity. British Medical Bulletin, 69(1), 129-141. https://doi.org/10.1093/bmb/ldh007

Bransford, J., Brown, A., \& Cocking, R. (2000). How people learn: Mind, brain, experience, and school (Exp. ed.). Washington, DC: National Academy Press.

Chapman, J. W., Lambourne, R., \& Silva, P. A. (1990). Some antecedents of academic self-concept: A longitudinal study. British Journal of Educational Psychology, 60(2), 142-152. https://doi.org/10.1111/j.2044-8279.1990.tb00931.x

Chumak-Horbatsch, R. (2012). Linguistically appropriate practice. A guide for working with young immigrant children. New York, USA: University of Toronto Press.

Cohen, L., Manion, L., \& Morrison, K. (2018). Research methods in education. London: Routledge.

Collins, M., \& Amabile, T. (1999). Motivation and creativity. In R. J. Sternberg (Ed.), Handbook of creativity (pp. 297-312). New York: Cambridge University Press.

Csikszentmihalyi, M. (2014). Flow and the foundations of positive psychology the collected works of Mihaly Csikszentmihalyi. Dordrecht: Springer Netherlands.

Cummins, J. (2001a). Bilingual children's mother tongue: Why is it important for education? Sprogforum, 7(19), 15-20.

Cummins, J. (2001b). Negotiating identities: Education for empowerment in a diverse society (2nd ed.). Los Angeles, CA: California Association for Bilingual Education.

Cummins, J. (2017). Multilingualism in classroom instruction: "I think it's helping my brain grow". Scottish Languages Review, 33, 5-18.

Delpit, L. (2002). The skin that we speak: Thoughts on language and culture in the classroom. New York: The New Press.

Deunk, M., Doolaard, S., Smale-Jacobse, A., \& Bosker, R. J. (2015). Differentiation within and across classrooms: A systematic review of studies into the cognitive effects of differentiation practices. Groningen: GION.

Dryden-Peterson, S. (2015). The educational experiences of refugee children in countries of first asylum. Washington, DC: Migration Policy Institute.

García, O. (2009a). Bilingual education in the 21st century: A global perspective. Oxford: WileyBlackwell.

García, O. (2009b). Education, multilingualism, and translanguaging in the 21st century. In T. Skutnabb-Kangas, R. Phillipson, A. K. Mohanty, \& M. Panda (Eds.), Multicultural education for social justice: Globalizing the local (pp. 140-158). Bristol, UK: Multilingual Matters.

García, O. (2009c). Emergent bilinguals and TESOL: What's in a name? TESOL Quarterly, 43(2), 322326.

Gardner, H. (1983). Frames of mind: The theory of multiple intelligences. New York: Basic Books.

Gay, G. (2010). Culturally responsive teaching: Theory, research, and practice. New York, NY: Teachers College Press. 
Gee, J. P. (2004). Situated language and learning: A critique of traditional schooling. New York: Routledge.

Geel, M. V., Keuning, T., Frèrejean, J., Dolmans, D., Merriënboer, J. V., \& Visscher, A. J. (2018). Capturing the complexity of differentiated instruction. School Effectiveness and School Improvement, 30(1), 51-67. https://doi.org/10.1080/09243453.2018.1539013

Gibson, G. E. (2012). Interviews and focus groups with children: Methods that match children's developing competencies. Journal of Family Theory \& Review, 4(2), 148-159.

Gkaintartzi, A., Kiliari, A., \& Tsokalidou, R. (2016). Heritage language maintenance and education in the Greek sociolinguistic context: Albanian immigrant parents' views. Cogent Education, 3(1), 1-17. https://doi.org/10.1080/2331186x.2016.1155259

Greenleaf, R. K. (2003). Motion and emotion. Principal Leadership, 3(9), 14-19.

Hajisoteriou, C. (2012). Intercultural education set forward: Operational strategies and procedures in Cypriot classrooms. Intercultural Education, 23(2), 133-146.

Heckmann, F. (2008). Education and migration strategies for integrating migrant children in European schools and societies: A synthesis of research findings for policy-makers. Luxembourg: European Commission.

Hollie, S. (2012). Culturally and linguistically responsive teaching and learning: Classroom practices for student success. Huntington Beach, CA: Shell Education.

Janta, B., \& Harte, E. (2016). Education of migrant children: Education policy responses for the inclusion of migrant children in Europe. https://doi.org/10.7249/rr1655

Johnsen, S., Haensly, P., Ryser, G., \& Ford, R. (2002). Changing general education classroom practices to adapt for gifted students. Gifted Child Quarterly, 46, 45-63.

Johnson, A. P. (2012). A short guide to action research. Upper Saddle River, NJ: Pearson.

Koutselini, M. (2006). Diaforopoiisi didaskalias - mathisis se taxeis miktis ikanotitas: Filosofía kai ennoia prosegiseis kai efarmoges [Differentiating instruction-learning in mixed ability classes: Philosophy and concept approaches and applications]. Tomos A'. Nicosia.

Koutselini, M. (2008). Listening to students' voices for teaching in mixed ability classrooms: Presuppositions and considerations for differentiated instruction. Learning and Teaching, 1(1), 17-30.

Koutselini, M., \& Agathangelou, S. (2009). Human rights and teaching: Equity as praxis in mixed ability classrooms. In P. Cunningham (Ed.), Proceedings of the eleventh Conference of the Children's Identity and Citizenship in Europe (CICE) thematic network: human rights and citizenship education (CD-ROM) (pp. 237-244). London: CiCe Publication.

Krumm, H. (2007). Profiles instead of levels: The CEFR and its (ab)uses in the context of migration. The Modern Language Journal, 91(4), 667-669.

Krumm, H., \& Plutzar, V. (2008). Tailoring language provision and requirements to the needs and capacities of adult migrants. Council of Europe. Retrieved from https://rm.coe.int/16802fc1c8

Ladson-Billings, G. (2001). Crossing over to Canaan: The journey of new teachers in diverse classrooms. San Francisco: Jossey-Bass.

Lawrence-Brown, D. (2004). Differentiated instruction: Inclusive strategies for standards-based learning that benefit the whole class. American Secondary Education, 32(3), 34-62. Retrieved from https://www.jstor.org/stable/41064522 
Long, M. (2015). Second-language acquisition and task-based language teaching. Oxford, UK: Wiley Blackwell.

Lucas, T., \& Villegas, A. M. (2011). A framework for preparing linguistically responsive teachers. In T. Lucas (Ed.), Teacher preparation for linguistically diverse classrooms: A resource for teacher educators (pp. 55-72). New York, NY: Routledge.

Lynch, K., \& Baker, J. (2005). Equality in education: The importance of equality of condition. Theory and Research in Education, 3(2), 131-164.

Manyak, P. (2006). Fostering biliteracy in a monolingual milieu: Reflections on two counterhegemonic English immersion classes. Journal of Early Childhood Literacy, 6(3), 241-66.

Marzano, R. J., Marzano, J. S., \& Pickering, D. J. (2003). Classroom management that works: Research-based strategies for every teacher. Alexandria, Virginia USA: ASCD.

Nieto, S. (2012). Affirming diversity: The sociopolitical context of multicultural education. New York: Longman.

Richards, H. V., Brown, A. F., \& Forde, T. B. (2007). Addressing diversity in schools: Culturally responsive pedagogy. Teaching Exceptional Children, 39(3), 64-68.

Santamaría, L. J. (2009). Culturally responsive differentiated instruction: Narrowing gaps between best pedagogical practices benefiting all learners. Teachers College Record, 111(1), 214-247.

Sfyroera, M. (2004). Diaforopoiimeni Paidagogiki [Differentiated pedagogy]. Athens: IP.E.P.TH University of Athens.

Sharan, Y., \& Sharan, S. (1992). Expanding cooperative learning through group investigation. New York: Teachers College Press.

Somekh, B. (2006). Action research: A methodology for change and development. Maidenhead, UK: Open University Press.

Stronge, J. (2002). Qualities of effective teachers. Alexandria, Virginia USA: ASCD.

Tomlinson, C. A. (1999). The differentiated classroom: Responding to the needs of all learners. Alexandria, Virginia USA: Association for Supervision and Curriculum Development.

Tomlinson, C.A. (2001). Differentiated instruction in the regular classroom. Understanding our Gifted, 14(1), 3-6.

Tomlinson, C. A. (2003). Fulfilling the promise of the differentiated classroom: Strategies and tools for responsive teaching. Alexandria, Virginia USA: Association for Supervision and Curriculum Development.

Tomlinson, C. A., Brighton, C., Hertberg, H., Callahan, C. M., Moon, T. R., Brimijoin, K., ... Reynolds, T. (2003). Differentiating instruction in response to student readiness, interest, and learning profile in academically diverse classrooms: A review of literature. Journal for the Education of the Gifted, 27(2-3), 119-145. https://doi.org/10.1177/016235320302700203

Tomlinson, C. A., Brimijoin, K., \& Narvaez, L. (2008). The differentiated school: Making revolutionary changes in teaching and learning. Alexandria, Virginia USA: Association for Supervision and Curriculum Development.

Tomlinson, C. A., \& Eidson, C. C. (2003). Differentiation in practice: A resource guide for differentiating curriculum, grades K-5. Alexandria, Virginia USA: Association for Supervision and Curriculum Development.

Tomlinson, C. A., \& Imbeau, M. B. (2010). Leading and managing a differentiated classroom. Alexandria, Virginia USA: Association for Supervision and Curriculum Development. 
Tsokalidou, R. (2005). Raising 'bilingual awareness' in Greek primary schools. International Journal of Bilingual Education and Bilingualism, 8(1), 48-61.

Tsokalidou, R. (2012). Choros gia dyo. Themata diglossias kai ekpaidefsis [Place for two. Issues of bilingualism and education]. Thessaloniki: Zigos.

Valiandes, S., \& Koutselini, M. (2008). Differentiation instruction in mixed ability classrooms, the whole picture: Presuppositions and issues, presented at the Annual Meeting of the International Academy of Linguistics, Behavioral and Social Sciences, Newport Beach, California.

Valiandes, S., \& Koutselini, M. (2009). Application and evaluation of differentiation instruction in mixed ability classrooms, presented at the 4th Hellenic Observatory PhD Symposium, 25-26 June 2009, LSE.

Valiandes, S., Neophytou, L., \& Hajisoteriou, C. (2018). Establishing a framework for blending intercultural education with differentiated instruction. Intercultural Education, 29(3), 379398. https://doi.org/10.1080/14675986.2018.1441706

Van Tassel-Baska, J. (1992). Educational decision making on acceleration and grouping. Gifted Child Quarterly, 36, 68-72.

White, M. D., \& Marsh, E. E. (2006). Content analysis: A flexible methodology. Library Trends, 55(1), 22-45.

Wiese, E. B. (2010). Culture and migration: Psychological trauma in children and adolescents. Traumatology, 16(4), 142-152. https://doi.org/10.1177/1534765610388304

Wong Fillmore, L. (2000). Loss of family languages: Should educators be concerned? Theory Into Practice, 39(4), 203-210. http://dx.doi.org/10.1207/s15430421tip3904 3

Ziomas, D., Capella, A., \& Konstantinidou, D. (2017). Integrating refugee and migrant children into the educational system in Greece (Report No. 67). Brussels: European Commission. 